\title{
Epigenetic Control of Immunity
}

\author{
Meinrad Busslinger ${ }^{1}$ and Alexander Tarakhovsky ${ }^{2}$ \\ ${ }^{1}$ Research Institute of Molecular Pathology, Vienna Biocenter, A-1030 Vienna, Austria; ${ }^{2}$ Laboratory of Lymphocyte \\ Signaling, The Rockefeller University, New York, New York 10021 \\ Correspondence: busslinger@imp.ac.at and tarakho@mail.rockefeller.edu
}

\section{SUMMARY}

Immunity relies on the heterogeneity of immune cells and their ability to respond to pathogen challenges. In the adaptive immune system, lymphocytes display a highly diverse antigen receptor repertoire that matches the vast diversity of pathogens. In the innate immune system, the cell's heterogeneity and phenotypic plasticity enable flexible responses to changes in tissue homeostasis caused by infection or damage. The immune responses are calibrated by the graded activity of immune cells that can vary from yeast-like proliferation to lifetime dormancy. This article describes key epigenetic processes that contribute to the function of immune cells during health and disease.

\section{Outline}

1 Introduction to the adaptive immune system

2 Lineage commitment in the lymphoid system

3 Lineage plasticity in the immune system

4 Epigenetic control of $\mathrm{V}(\mathrm{D}) \mathrm{J}$ recombination

5 Role of epigenetic regulators in lymphoid malignancies
6 Chromatin-mediated control of the inflammatory response

7 "Histone mimicry" and its implication for regulation of inflammation

8 Concluding remarks

References

Editors: C. David Allis, Marie-Laure Caparros, Thomas Jenuwein, and Danny Reinberg

Additional Perspectives on Epigenetics available at www.cshperspectives.org

Copyright (C 2014 Cold Spring Harbor Laboratory Press; all rights reserved; doi: 10.1101/cshperspect.a019307

Cite this article as Cold Spring Harb Perspect Biol 2014;6:a019307 


\section{OVERVIEW}

The immune system has a nearly unlimited capacity to respond to environmental triggers. The enormous adaptive potential of the immune system is governed by the mechanisms that enable potential recognition of any "foreign" or "self" triggers, as well as flexibility of immune cell responses to signals of various types and duration. Two types of the immune response, innate and adaptive, provide a comprehensive defense against environmental hazards and also eliminate nonfunctional or malignantly transformed cells.

The innate response involves recognition of nonvariable environmental components, such as pathogen-derived nucleic acids or lipids and noxious substances or venoms. The adaptive immune response relies on a highly diverse immune cell repertoire that is generated through the random arrangement of the antigen receptor genes in B and $T$ lineage cells. The function of the immune system depends also on a highly robust and stringently orchestrated process of hematopoietic cell differentiation, where cells of different types are produced at constant rates and maintain their homeostatic balance through the life of the organism.
A combination of the relatively rigid patterns of immune cell differentiation and "fluid" patterns of responses implies the existence of mechanisms that limit the breadth of phenotypic variation during the generation of immune cells of a defined lineage but increase these variations in mature cells to match the variety and abundance of the environmental triggers. These overreaching models suggest the existence of potentially nonoverlapping epigenetic processes that minimize the variability of the developmental choices within cells of a given lineage, but increase the stochasticity of the differentiated immune cell adaptation to their environment.

The following article narrates B-cell development as an example of a highly hierarchical and tightly controlled process governed by well-established transcriptional networks and less understood epigenetic processes. We also discuss the epigenetic regulation of the inflammatory responses that require flexible adaptation to diverse environmental challenges. Finally, we show how the very basic biochemical principles of epigenetic regulation, involving interaction between the histones and effector proteins, could be used for selective interference with immune responses during health and disease. 


\section{INTRODUCTION TO THE ADAPTIVE IMMUNE SYSTEM}

The lymphoid system is well suited to study epigenetic mechanisms controlling lineage commitment and differentiation; the developmental pathways from the hematopoietic stem cell (HSC) to mature lymphocytes have been elucidated in great detail (Fig. 1). Commitment of the common lymphoid progenitor (CLP) to the B-lymphoid lineage initiates B-cell development in the bone marrow that is characterized by sequential rearrangements of the immunoglobulin heavy-chain $(\mathrm{IgH})$ locus in pro-B cells and immunoglobulin light-chain ( $I g L)$ genes in pre-B cells. Following elimination of autoreactive B lymphocytes, immature B cells migrate to peripheral lymphoid organs and differentiate into mature B cells that, on antigen encounter, develop into immunoglobulin-secreting plasma cells (Fig. 1). Lymphoid progenitors that flux through the blood stream enter the thymus, where they initiate T-cell development and undergo rearrangements at the T-cell receptor (TCR) $\beta, \gamma$, and $\delta$ loci in early T-cell progenitors $\left(\mathrm{CD} 4^{-} \mathrm{CD} 8{ }^{-}\right.$double negative, $\left.\mathrm{DN}\right)$. Successful recombination of TCR $\gamma$ and TCR $\delta$ genes results in the development of $\gamma \delta \mathrm{T}$ cells. In-frame TCR $\beta$ rearrangements activate preTCR signaling and subsequent differentiation to $\mathrm{CD} 4^{+}$ $\mathrm{CD}^{+}$double-positive (DP) thymocytes that undergo recombination at the TCR $\alpha$ locus (Fig. 1). Following positive and negative selection, naïve $\mathrm{CD} 4^{+}$and $\mathrm{CD} 8^{+}$single-positive (SP) T cells emerge that further differentiate into distinct $\mathrm{CD} 4^{+} \mathrm{T}$ helper cell types or $\mathrm{CD} 8^{+}$cytotoxic $\mathrm{T}$ cells in peripheral lymphoid organs (Fig. 1). Here, we discuss those epigenetic mechanisms that have been shown to play an important role in the control of lymphopoiesis and immunity.

\section{LINEAGE COMMITMENT IN THE LYMPHOID SYSTEM}

\subsection{Lymphoid Gene Priming in Hematopoietic Progenitors}

Early lymphopoiesis is controlled by signaling through the c-Kit, Flt3, and IL-7 receptors as well as by cell-intrinsic transcription factors, such as the zinc-finger transcription factor Ikaros and the Ets-domain protein PU.1, which are essential for the generation of CLPs (Fig. 2A) (Nutt and Kee 2007). The up-regulation of selected lymphoid genes and the simultaneous down-regulation of self-renewal-associated genes constitute the first sign of early lymphopoiesis in multipotent progenitors (MPPs). This priming of lymphoid gene expression is under positive control by the helix-loop-helix protein E2A (Dias et al. 2008) and the transcription factor Ikaros ( $\mathrm{Ng}$ et al. 2009) that regulates its target genes through interaction with the Mi- $2 \beta$ nucleosome-remodeling and histone-deactylase (NuRD) complex (Zhang et al. 2012b). Lymphoid gene priming is antagonized by the Bmil-containing Polycomb-repressive complex 1 (PRC1) that promotes HSC renewal and function (Oguro et al. 2010). In addition, both PRC1 and Polycomb-repressive complex 2 (PRC2) are responsible for silencing the B-cell-specific transcription factor genes Ebf1 and Pax5 in MPPs and lymphoid progenitors by establishing the repressive histone marks H2AK119ub1 and H3K27me3 at their promoters (Decker et al. 2009; Oguro

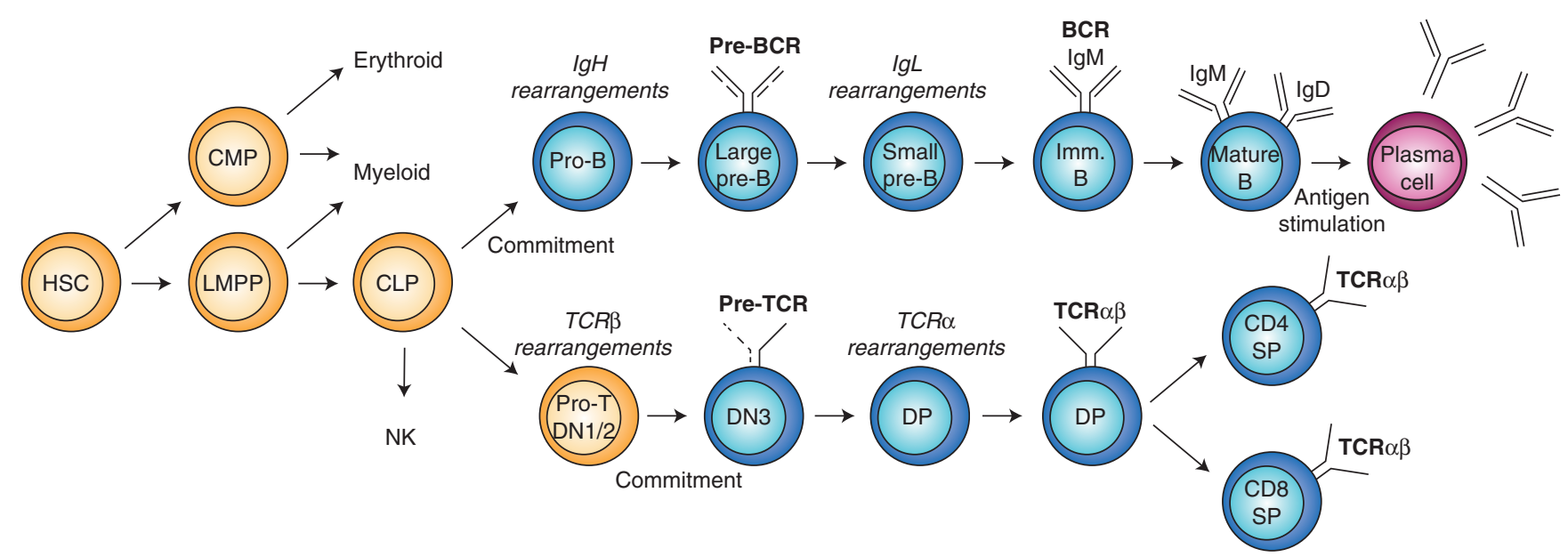

Figure 1. Schematic diagram of B- and T-cell development. Hematopoietic stem cells (HSCs) differentiate via the indicated developmental stages to immunoglobulin-secreting plasma cells or CD4 ${ }^{+}$helper and $\mathrm{CD} 8^{+}$cytotoxic $\mathrm{T}$ cells. LMPP, lymphoid-primed multipotent progenitors; CMP, common myeloid progenitor; CLP, common lymphoid progenitor; DN, double negative; DP, double positive; SP, single positive. Orange, uncommitted progenitors; blue, committed lymphocytes; red, plasma cell. 


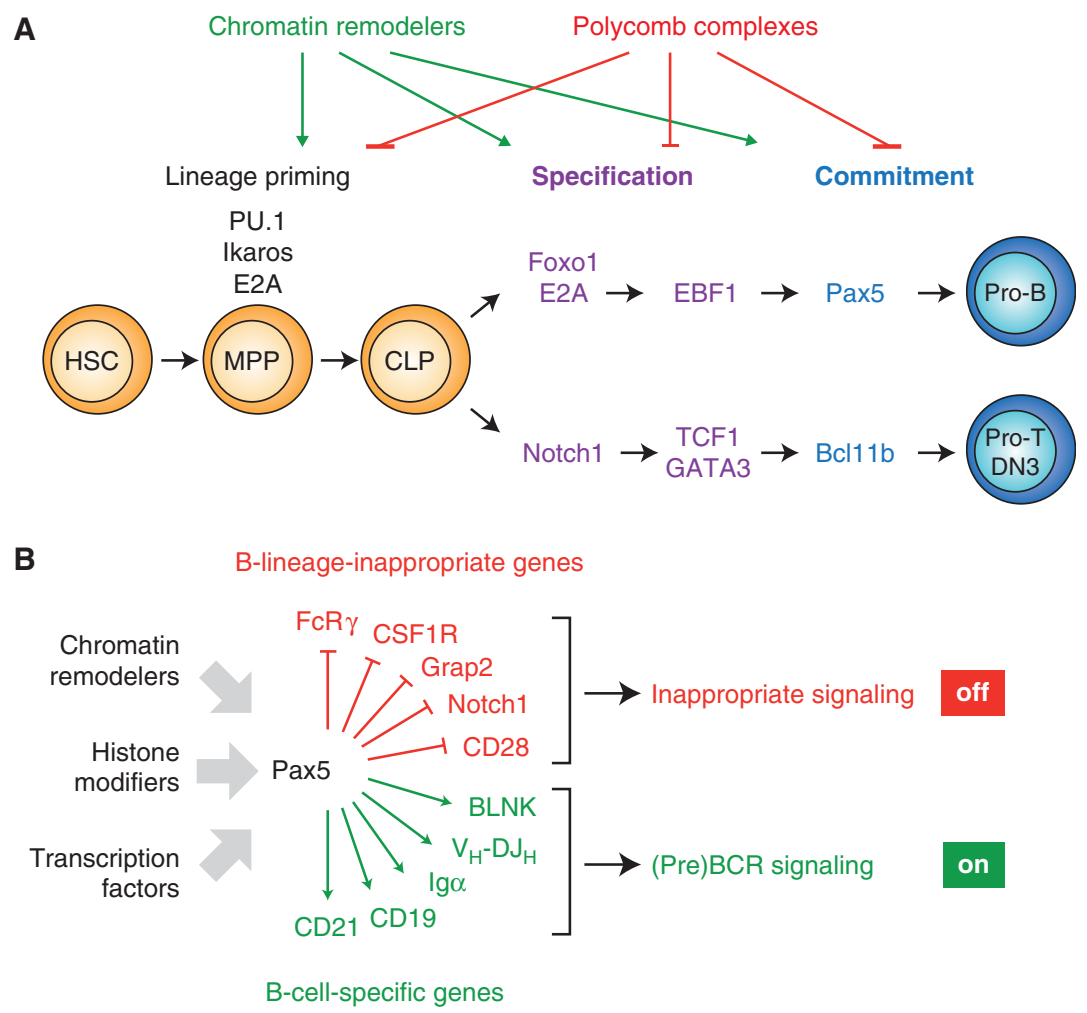

Figure 2. Transcriptional control of early lymphopoiesis. (A) Progenitors of the B- and T-cell lineages develop from the HSC under the control of the indicated transcription factors. (B) Pax5 activates B-cell-specific genes involved in (pre) B-cell receptor (BCR) signaling, and represses lineage-inappropriate genes of the myeloid (FcR $\gamma, \mathrm{CSF} 1 \mathrm{R})$ or Tlymphoid (Notch1, CD28, Grap2) pathways. See Revilla-i-Domingo et al. (2012) for a more complete list of regulated Pax5 target genes.

et al. 2010). Remarkably, loss of the Polycomb protein Bmi1 is sufficient to activate the transcription of Ebf1, Pax5, and their target genes in $\mathrm{Bmil}^{-/-}$MPPs (Oguro et al. 2010). Hence, Polycomb-mediated silencing prevents premature activation of the B-cell gene expression program before the onset of B lymphopoiesis.

\subsection{Control of Lymphoid Lineage Commitment}

B-cell commitment depends on sequential activity of the instructive transcription factors E2A, EBF1, and Pax5 during the development of CLPs to pro-B cells (Fig. 2A) (Nutt and Kee 2007). The early B-cell factor EBF1, with the help of E2A and Foxo1, specifies the B-cell lineage by activating the expression of B-lymphoid genes in uncommitted pre-proB cells (Györy et al. 2012). Pax 5 subsequently controls B-cell commitment by restricting the developmental potential of lymphoid progenitors to the B-cell lineage (Nutt et al. 1999; Medvedovic et al. 2011). Pax5 fulfills a dual role at B-cell commitment by repressing a multitude $(\sim 230)$ of B-lineage-inappropriate genes to suppress alternative lineage op- tions and by simultaneously activating many $(\sim 120)$ B-cell-specific genes to promote B-cell development (Fig. 2B) (Nutt et al. 1999; Revilla-i-Domingo et al. 2012). Several of the activated Pax5 target genes code for essential components of ( pre)B-cell receptor (BCR) signaling (Ig $\alpha$, BLNK, CD19, CD21; Fig. 2B), indicating that the transactivation function of Pax 5 facilitates signal transduction from the pre-BCR and BCR, which constitute important checkpoints in B-cell development. On the other hand, the repressed Pax 5 target genes code for a plethora of secreted proteins, cell adhesion molecules, signal transducers, and nuclear proteins that are expressed in erythroid, myeloid, and/or T-lymphoid cells (Fig. 2B) (Delogu et al. 2006; Revilla-i-Domingo et al. 2012). Among them are the Csf1r (M-CSFR) and Notch1 genes that nicely exemplify how their Pax5-dependent down-regulation renders committed $\mathrm{B}$ cells no longer responsive to the myeloid cytokine M-CSF or to T-cell-inducing Notch ligands (Medvedovic et al. 2011). Hence, the repression function of Pax 5 is as important as its activation function because it contributes to B-cell commitment by shutting down inappropriate signaling systems. 
Pax 5 controls gene expression by inducing the formation of active enhancers and promoters at activated target genes and by simultaneously promoting the loss of active DNase I hypersensitive sites at repressed target genes (McManus et al. 2011; Revilla-i-Domingo et al. 2012). Pax5 generates these chromatin and transcription changes by recruiting chromatin-remodeling (BAF), histone-modifying (MLL, CBP, NCoR1), and basal transcription factor (TFIID) complexes to its target genes (McManus et al. 2011). Hence, Pax5 functions as an epigenetic regulator to reprogram gene expression at B-cell commitment.

On entry into the thymus, lymphoid progenitors are exposed to the Notch ligand Delta-like 4 on thymic epithelial cells that activates Notch1 signaling and the T-cell developmental program (Fig. 2A) (Radtke et al. 2010). Notch1 and its downstream transcription factors TCF1 (Tcf7) and GATA3 are essential for the formation of the earliest T-cell precursors and subsequent development of pro-T (DN) cells (Ting et al. 1996; Radtke et al. 2010; Weber et al. 2011). Commitment to the T-cell lineage is further controlled by the transcription factor Bcl11b at the transition to the DN3 cell stage (Fig. 2A) ( Li et al. 2010). Little is known, however, about how these transcription factors shape the epigenetic landscape and regulate the transcriptional network directing early T-cell development.

\section{LINEAGE PLASTICITY IN THE IMMUNE SYSTEM}

\subsection{Lineage Reprogramming by Ectopic Transcription Factors}

The groundbreaking discovery of Takahashi and Yamanaka (2006) showed that most somatic cell types can be epigenetically reprogrammed by ectopic expression of the four transcription factors Oct4, Sox2, Klf4, and c-Myc into pluripotent stem cells with properties similar to embryonic stem cells. Previously, it was already known that forced expression of the myeloid transcription factor $\mathrm{C} / \mathrm{EBP} \alpha$ induces rapid transdifferentiation of $\mathrm{B}$ lymphocytes into functional macrophages (Fig. 3) (Xie et al. 2004). Mecha-

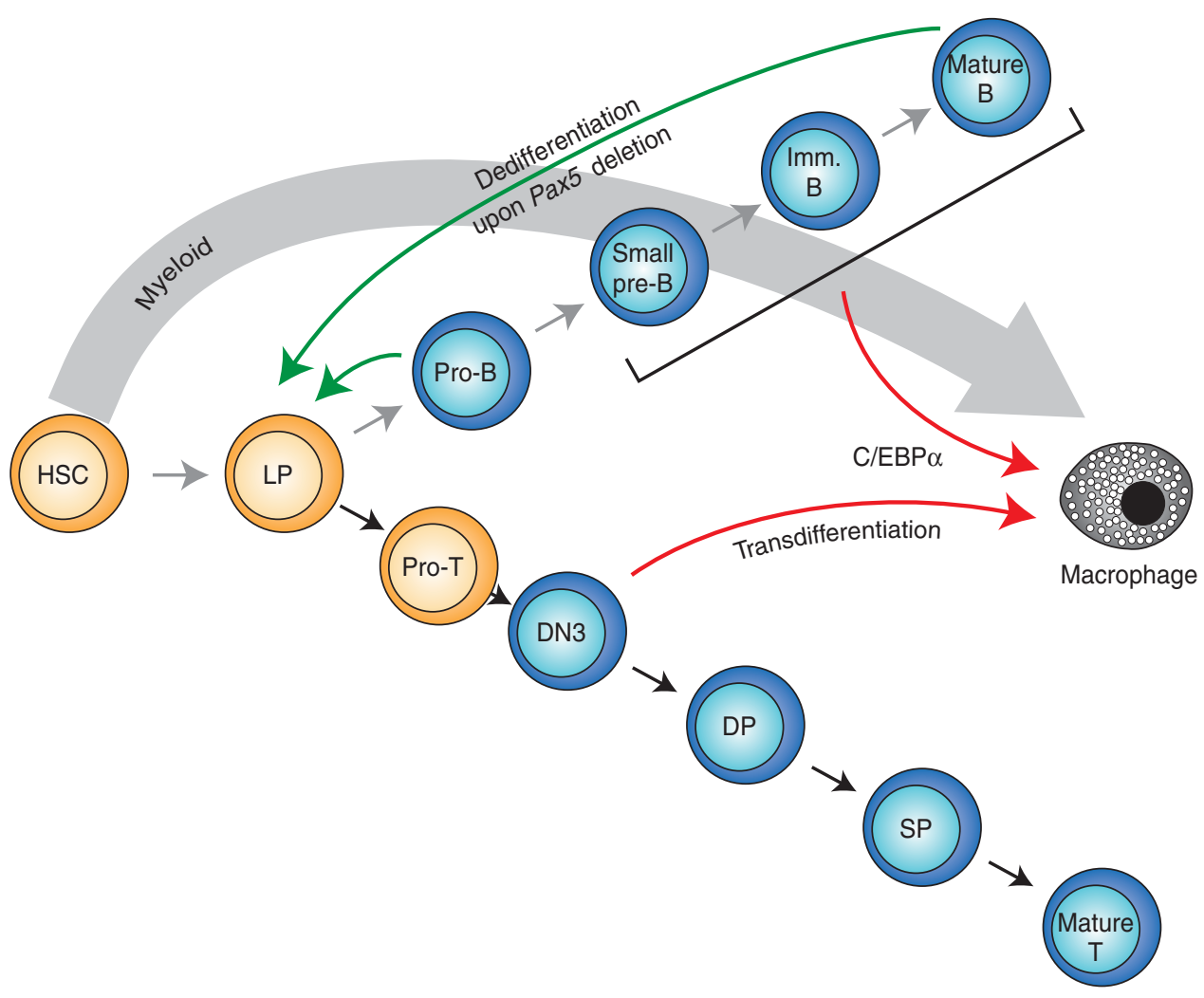

Figure 3. Developmental plasticity of B lymphocytes. Committed CD19 ${ }^{+}$B lymphocytes and committed DN3 thymocytes undergo rapid transdifferentiation in vitro to macrophages in response to forced $\mathrm{C} / \mathrm{EBP} \alpha$ expression (red arrows) (Xie et al. 2004). Conditional Pax5 deletion allows committed pro-B cells and mature B cells to dedifferentiate in vivo to uncommitted lymphoid progenitors (LPs; green arrows) that subsequently develop into other hematopoietic cell types in the bone marrow or T cells in the thymus (black arrows) (Cobaleda et al. 2007). Committed lymphocytes are shown in blue. 
nistic analysis of this transdifferentiation process revealed that pre- $\mathrm{B}$ cells are converted by $\mathrm{C} / \mathrm{EBP} \alpha$ activity into macrophage-like cells within $2-3 \mathrm{~d}$ by loss of the B-cell expression signature and simultaneous activation of the macrophage-specific gene expression program (Bussmann et al. 2009). Likewise, ectopic C/EBP $\alpha$ expression can efficiently reprogram committed DN3 thymocytes into functional macrophages (Fig. 3) (Laiosa et al. 2006). This myeloid lineage conversion is, however, prevented in the presence of Notch signaling (Laiosa et al. 2006), indicating that lymphoid signals and transcription factors can antagonize the $\mathrm{C} / \mathrm{EBP} \alpha$-mediated reprogramming of lymphocytes to macrophages.

\subsection{Conversion of Mature B Cells into Functional T Cells}

The last differentiation step in the B-cell pathway has characteristic features of a lineage switch because it results in a radical change from a Pax5-dependent expression program in mature B cells to a Blimp1-dominated transcription program in plasma cells (Fig. 1) (Shaffer et al. 2002; Delogu et al. 2006). The developmental potential of mature B cells may thus be plastic rather than restricted to the $\mathrm{B}$-cell fate. Consistent with this idea, mature B cells seem to lose their B-cell identity on Pax5 loss because they down-regulate Bcell-specific genes and reactivate lineage-inappropriate genes (Delogu et al. 2006; Revilla-i-Domingo et al. 2012). The destiny of the Pax5-deficient mature B cells was analyzed by conditional Pax 5 deletion in highly purified B cells followed by intravenous injection of the Pax5-deleted B cells into T-cell-deficient mice (Cobaleda et al. 2007). These experiments showed that the loss of Pax 5 allows mature B cells from peripheral lymphoid organs to dedifferentiate in vivo back to early uncommitted progenitors that migrate to the bone marrow (Fig. 3) (Cobaleda et al. 2007). These dedifferentiated progenitors are subsequently able to develop into macrophages and functional $\mathrm{T}$ cells (Fig. 3) (Cobaleda et al. 2007). Hence, loss of the B-cell identity factor Pax5 is able to induce dedifferentiation of mature B lymphocytes, which reveals a remarkable plasticity of these cells.

\section{EPIGENETIC CONTROL OF V(D)J RECOMBINATION}

\subsection{Developmental Regulation of Antigen Receptor Gene Rearrangements}

The guiding principle of the acquired immune system is that every newly generated lymphocyte recognizes a unique antigen and that the overall diversity of lymphocytes is great enough to counteract any possible antigen. To this end, B and $\mathrm{T}$ cells express lineage-specific antigen receptors that mediate antibody-dependent humoral or cellular immunity, respectively. The BCR consists of an immunoglobulin heavy-chain $(\operatorname{IgH})$ and an Igк or Ig $\lambda$ light-chain (IgL). T cells of the $\alpha \beta$ lineage, which comprise the majority of T lymphocytes in mouse and man, express the TCR $\beta$ polypeptide in association with $\operatorname{TCR} \alpha$, whereas the functionally distinct $\gamma \delta$ T cells contain TCR $\gamma$ paired with TCR $\delta$ on their cell surface. These antigen receptor proteins are encoded by large gene loci containing discontinuous variable $(\mathrm{V})$, diversity $(\mathrm{D})$, and joining $(\mathrm{J})$ gene segments that are assembled by $\mathrm{V}(\mathrm{D}) \mathrm{J}$ recombination into a functional gene during lymphocyte development (Fig. 4A). The multiplicity of D, $\mathrm{J}$, and especially $\mathrm{V}$ gene segments, combined with the randomness of their recombination, is responsible for the virtually unlimited diversity of the immune repertoire (Bassing et al. 2002).

The mechanics of $V(D) J$ recombination at the DNA level is rather simple. All V, D, and J gene segments are flanked by recombination signal sequences (RSSs) that consist of relatively conserved heptamer and nonamer elements separated by a spacer of either 12 or $23 \mathrm{bp}$. The lymphoidspecific recombinase proteins RAG1 and RAG2, assisted by high-mobility group proteins, assemble 12- and 23-bp RSSs into a synaptic complex and then generate double-strand DNA breaks between the RSSs and coding segments. These DNA breaks are subsequently processed and relegated by ubiquitous repair factors of the nonhomologous end-joining machinery to form coding and signal joints (Bassing et al. 2002).

The simplicity of the $\mathrm{V}(\mathrm{D}) \mathrm{J}$ recombination process at the DNA template level poses logistic problems for the assembly of the different antigen receptors because the RAG proteins are expressed in all immature B and T lymphocytes. Hence, stringent regulation must be in place to restrict the access of RAG proteins to only specific subsets of all of the recombination substrates (Yancopoulos and Alt 1985; Stanhope-Baker et al. 1996). V(D)J recombination is tightly controlled in a lineage- and stage-specific manner. Within the B-lymphoid lineage, the IgH locus is rearranged in pro-B cells before recombination of $I g \kappa$ and $I g \lambda$ genes in pre-B cells, whereas TCR $\beta$ and TCR $\alpha$ genes are rearranged in pro-T (DN) and DP thymocytes, respectively (Fig. 1). Moreover, $\mathrm{V}(\mathrm{D}) \mathrm{J}$ recombination of the IgH gene occurs in a defined temporal order with $\mathrm{D}_{\mathrm{H}^{-}} \mathrm{J}_{\mathrm{H}}$ rearrangements preceding $\mathrm{V}_{\mathrm{H}}-\mathrm{DJ} \mathrm{H}_{\mathrm{H}}$ recombination. Rearrangements of the TCR $\beta$ locus also proceed in the same order $\left(D_{\beta}-J_{\beta}\right.$ before $\mathrm{V}_{\beta}-\mathrm{DJ}_{\beta}$ ) during pro-T-cell development. Control mechanisms must therefore exist to shield all V genes from RAGmediated cleavage during D-J recombination and to facilitate rearrangement of only one out of $100 \mathrm{~V}$ genes 

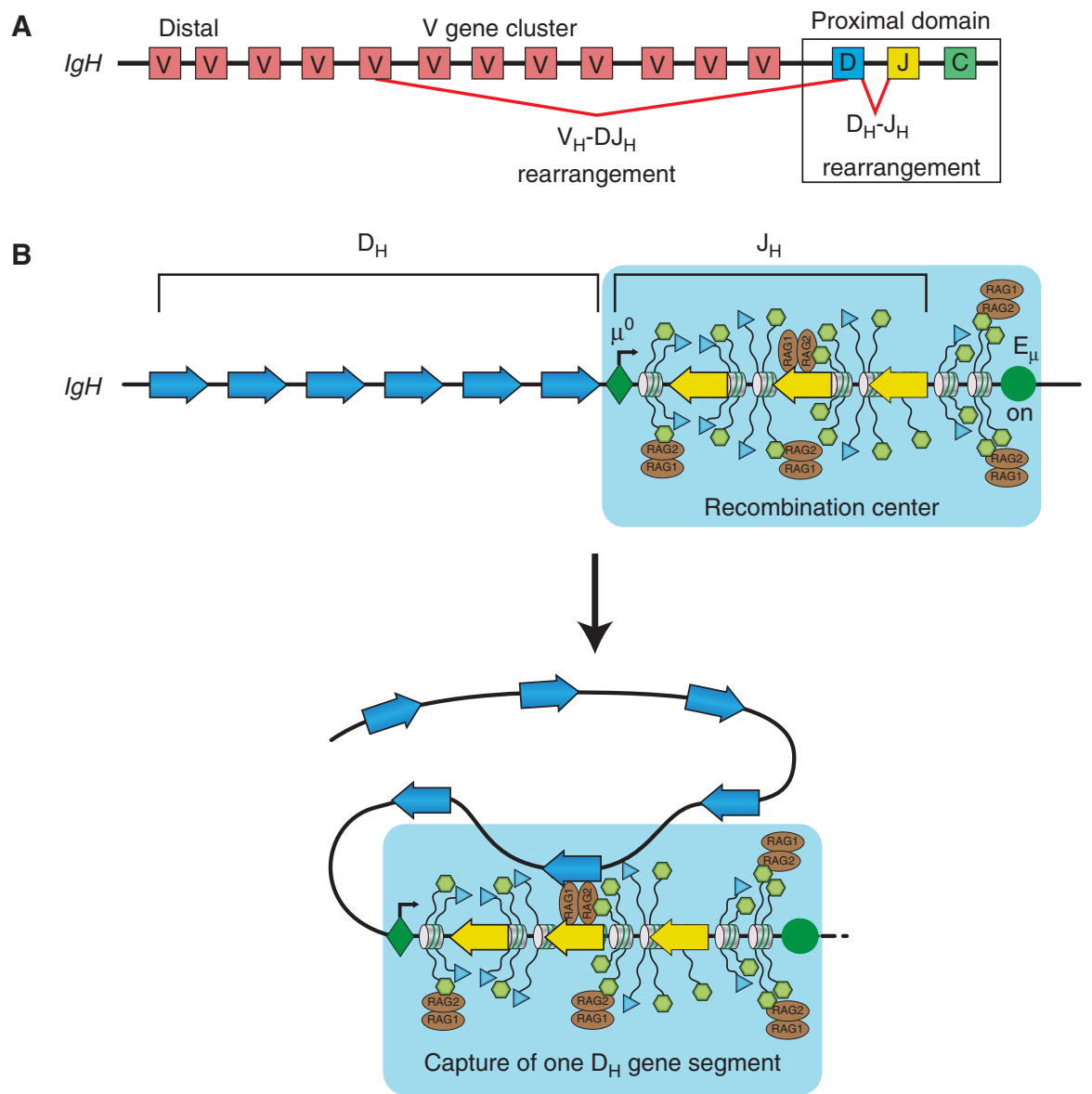

Figure 4. Involvement of RAG1/2 in the formation of recombination centers. (A) Structure of the IgH locus. The murine $I g H$ locus is composed of the $3^{\prime}$ proximal region of $270 \mathrm{~kb}$ length consisting of $16 \mathrm{D}_{\mathrm{H}}, 4 \mathrm{~J}_{\mathrm{H}}$, and $8 \mathrm{C}_{\mathrm{H}}$ gene segments and of the distal $\mathrm{V}_{\mathrm{H}}$ gene cluster extending over a $2.5-\mathrm{Mb}$ region containing $200 \mathrm{~V}_{\mathrm{H}}$ genes. $(B)$ The recombination center model. In lymphoid progenitors, the proximal $\mathrm{J}_{\mathrm{H}}$ gene region of the $I g H$ locus is activated as a recombination center under the control of the $\mu^{0}$ promoter and $\mathrm{E}_{\mu}$ enhancer. Binding of the RAG2 PHD finger to the active $\mathrm{H} 3 \mathrm{~K} 4 \mathrm{me} 3$ modification (green hexagons) in the recombination center recruits the RAG1/2 complex (brown oval), whose binding is further stabilized by the interaction of RAG1 with the $\mathrm{J}_{\mathrm{H}}$ RSS element (arrowhead). The tethered RAG1/2 complex captures one of several $\mathrm{D}_{\mathrm{H}}$ gene segments followed by $\mathrm{D}_{\mathrm{H}^{-}} \mathrm{J}_{\mathrm{H}}$ recombination. Blue triangles indicate acetylated lysine residues of histone $\mathrm{H} 3$.

during V-DJ recombination. Consequently, the process of antigen receptor generation entirely depends on accurate regulation of the accessibility of RSSs for the RAG1/2 recombinase.

Successful V-DJ recombination of the IgH or TCR $\beta$ gene leads to expression of the Ig $\mu$ or TCR $\beta$ protein as part of the pre-BCR or pre-TCR complex that acts as an important checkpoint to inhibit V-DJ recombination of the second, DJ-rearranged allele and to promote development to pre-B cells or DP thymocytes that initiate $\operatorname{IgL}$ or TCR $\alpha$ gene rearrangements, respectively (Fig. 1). Expression of a signaling-competent BCR or TCR subsequently arrests $\mathrm{V}(\mathrm{D}) \mathrm{J}$ recombination by transcriptional repression of Rag1/2 genes in immature B or T cells (Jankovic et al. 2004). Signaling of an autoreactive BCR can, however, re- start immunoglobulin light-chain gene rearrangement that results in the generation of a BCR with novel antigen specificity (Jankovic et al. 2004). Moreover, signaling of the cytokine IL-7 via the transcription factor STAT5 is essential for promoting recombination of the TCR $\gamma$ gene in pro-T cells (Ye et al. 2001) and for suppressing premature rearrangements at the IgK locus in pro-B cells (Malin et al. 2010). Hence, $V(D) J$ recombination is controlled not only intrinsically by developmental and lineage-specific nuclear mechanisms, but also extrinsically by signals generated at the cell surface.

The developmental and locus-specific constraints on $\mathrm{V}(\mathrm{D}) \mathrm{J}$ recombination are largely imposed at the epigenetic level (Jhunjhunwala et al. 2009). In nonlymphoid cells, the Ig and TCR genes are present in inaccessible chromatin 
because exogenously expressed RAG proteins readily cleave transfected episomal recombination substrates but not endogenous antigen receptor genes in kidney cells (Romanow et al. 2000). Moreover, recombinant RAG proteins added to isolated lymphocyte nuclei can only cleave the Ig or TCR gene that is actively undergoing $\mathrm{V}(\mathrm{D}) \mathrm{J}$ recombination at the developmental stage used for nuclei preparation (Stanhope-Baker et al. 1996). Hence, the lineage specificity and temporal ordering of gene rearrangements is caused by the sequential opening of local chromatin that renders specific RSSs accessible to the $\mathrm{V}(\mathrm{D}) \mathrm{J}$ recombinase.

\subsection{Chromatin-Mediated RAG Function at Recombination Centers}

Numerous promoters that are associated with V, D, and J segments of antigen receptor loci control the rearrangements of promoter-proximal sequences within relatively short distances (Bassing et al. 2002). These promoters give rise to germline transcription of short sense RNA from an unrearranged gene segment before $\mathrm{V}(\mathrm{D}) \mathrm{J}$ recombination (Yancopoulos and Alt 1985). Moreover, antisense intergenic transcription throughout the $\mathrm{V}_{\mathrm{H}}$ gene cluster is known to precede $\mathrm{V}_{\mathrm{H}}-\mathrm{DJ} \mathrm{H}_{\mathrm{H}}$ rearrangements at the $\mathrm{IgH}$ locus in pro-B cells, suggesting that these long antisense transcripts may direct chromatin remodeling of the $\mathrm{V}_{\mathrm{H}}$ gene domain (Bolland et al. 2004). An essential role for transcription in controlling locus accessibility is further indicated by the fact that enhancers exert long-range control of $\mathrm{V}(\mathrm{D}) \mathrm{J}$ recombination at antigen receptor loci (Bassing et al. 2002; Perlot et al. 2005). Deletion of endogenous enhancers strongly impairs $\mathrm{V}(\mathrm{D}) \mathrm{J}$ recombination of antigen receptor loci, whereas the insertion of additional lineage-specific enhancers leads to a novel V(D)J recombination pattern (Bassing et al. 2002; Perlot et al. 2005).

The occurrence of active chromatin at antigen receptor loci has been most extensively studied for the IgH locus. The intronic $\mathrm{E} \mu$ enhancer and adjacent $\mathrm{J}_{\mathrm{H}}$ segments are characterized by the abundant presence of the three active histone marks $\mathrm{H} 3 \mathrm{~K} 4 \mathrm{me} 2$, H3K4me3, and $\mathrm{H} 3 \mathrm{~K} 9 \mathrm{ac}$ in pro-B cells, where the $\mathrm{IgH}$ locus undergoes $\mathrm{V}(\mathrm{D}) \mathrm{J}$ recombination (Chakraborty et al. 2009; Malin et al. 2010). Local chromatin accessibility and histone acetylation are thereby established by the core $\mathrm{E} \mu$ enhancer itself (Chakraborty et al. 2009). Surprisingly, however, these three active histone modifications are largely absent at $\mathrm{V}_{\mathrm{H}}$ genes except for members of the $\mathrm{V}_{\mathrm{H}} 3609$ gene family in the distal $\mathrm{V}_{\mathrm{H}}$ gene cluster that carry detectable levels of $\mathrm{H} 3 \mathrm{~K} 9 \mathrm{ac}$ and $\mathrm{H} 3 \mathrm{~K} 4 \mathrm{me} 2$ (Malin et al. 2010). Hence, most $\mathrm{V}_{\mathrm{H}}$ genes do not show the active chromatin signature characteristic of expressed genes but must be accessible at the chromatin level in pro-B cells, where they undergo germline transcrip- tion and $\mathrm{V}_{\mathrm{H}}-\mathrm{DJ} \mathrm{H}_{\mathrm{H}}$ recombination (Yancopoulos and Alt 1985).

A possible explanation for this asymmetrical distribution of active chromatin at the $\mathrm{IgH}$ locus and other antigen receptor loci may be provided by the fact that the RAG2 protein contains at its carboxyl terminus a plant homeodomain (PHD) finger that specifically recognizes the active histone mark H3K4me3 (Matthews et al. 2007). Notably, the RAG2 protein can bind via its $\mathrm{PHD}$ finger to $\mathrm{H} 3 \mathrm{~K} 4 \mathrm{me} 3$ islands at active promoters throughout the genome ( $\mathrm{Ji}$ et al. 2010). More importantly, RAG2 also binds to the $\mathrm{H} 3 \mathrm{~K} 4 \mathrm{me} 3$ island at the J gene segments of the different antigen receptor loci $(\operatorname{IgH}, \operatorname{Ig} \kappa, T C R \beta$, and $T C R \alpha / \delta)$ once they become accessible during lymphocyte development (Fig. 4B) (Ji et al. 2010). The RAG1 protein interacts in a more restrictive manner only with the RSS elements of the accessible J gene segments and, thus, further contributes to the focal and stable recruitment of the RAG1/2 complex to the active chromatin region in the proximal region of antigen receptor loci referred to as the recombination center (Fig. 4B) (Ji et al. 2010). As exemplified for the IgH locus, the RAG1/2 complex, once tethered to the $\mathrm{J}_{\mathrm{H}}$ segments at the recombination center, can capture a partner RSS element of a $D_{H}$ segment to undergo synapse formation, which leads to $\mathrm{D}_{\mathrm{H}^{-}} \mathrm{J}_{\mathrm{H}}$ recombination in uncommitted lymphoid progenitors (Fig. 4B). As a consequence, the rearranged $\mathrm{D}_{\mathrm{H}}$ element becomes part of the active recombination center and is bound by the RAG1/2 complex that is now able to capture an RSS element of one of the many $\mathrm{V}_{\mathrm{H}}$ genes that are brought into close proximity by long-range contraction of the $\mathrm{V}_{\mathrm{H}}$ gene cluster (see Sec. 4.5), thus resulting in $\mathrm{V}_{\mathrm{H}^{-}}-\mathrm{DJ} \mathrm{H}_{\mathrm{H}}$ rearrangement in pro-B cells. The $\mathrm{H} 3 \mathrm{~K} 4 \mathrm{me} 3$-mediated focal targeting of the RAG1/2 endonuclease to the proximal recombination center is likely the reason for the fact that active chromatin is asymmetrically distributed at the proximal $\mathrm{J}_{\mathrm{H}}$ region and not throughout the $\mathrm{D}_{\mathrm{H}}$ and $\mathrm{V}_{\mathrm{H}}$ gene clusters in pro-B cells.

\subsection{Monoallelic Recombination by Homologous Pairing of Immunoglobin Loci}

Allelic exclusion ensures the productive rearrangement of only one of the two Ig alleles, which leads to the expression of a single antibody molecule with a unique antigen specificity in B cells. The process of allelic exclusion can be divided into two distinct steps. During the initiation phase, one of the two Ig alleles is selected to rearrange first, which precludes simultaneous recombination of the two alleles. Expression of the productively rearranged allele subsequently prevents recombination of the second allele by feedback inhibition, thus maintaining allelic exclusion. Similar to allelic exclusion of antigen receptor loci, X-chro- 
mosome inactivation in female cells leads to monoallelic expression of X-linked genes by random silencing of one $\mathrm{X}$ chromosome. Transient pairing of the two X chromosomes is known to initiate $\mathrm{X}$ inactivation by differentially marking one of the two chromosomes for subsequent epigenetic silencing (Bacher et al. 2006). Notably, the initiation of allelic exclusion also depends on homologous pairing of antigen receptor loci as revealed by three-dimensional (3D) DNA fluorescence in situ hybridization (3D DNA-FISH) (Hewitt et al. 2009). Transient pairing of the two IgH alleles is high in pre-pro- $\mathrm{B}$ and pro- $\mathrm{B}$ cells undergoing $\mathrm{D}_{\mathrm{H}^{-}} \mathrm{J}_{\mathrm{H}}$ and $\mathrm{V}_{\mathrm{H}}-\mathrm{DJ} \mathrm{J}_{\mathrm{H}}$ recombination, respectively, whereas the Ig $\kappa$ alleles frequently associate in pre- $\mathrm{B}$ and immature $\mathrm{B}$ cells during $\mathrm{V}_{\mathrm{K}}-\mathrm{J}_{\mathrm{K}}$ recombination (Fig. 5A) (Hewitt et al. 2009). Bind-

A
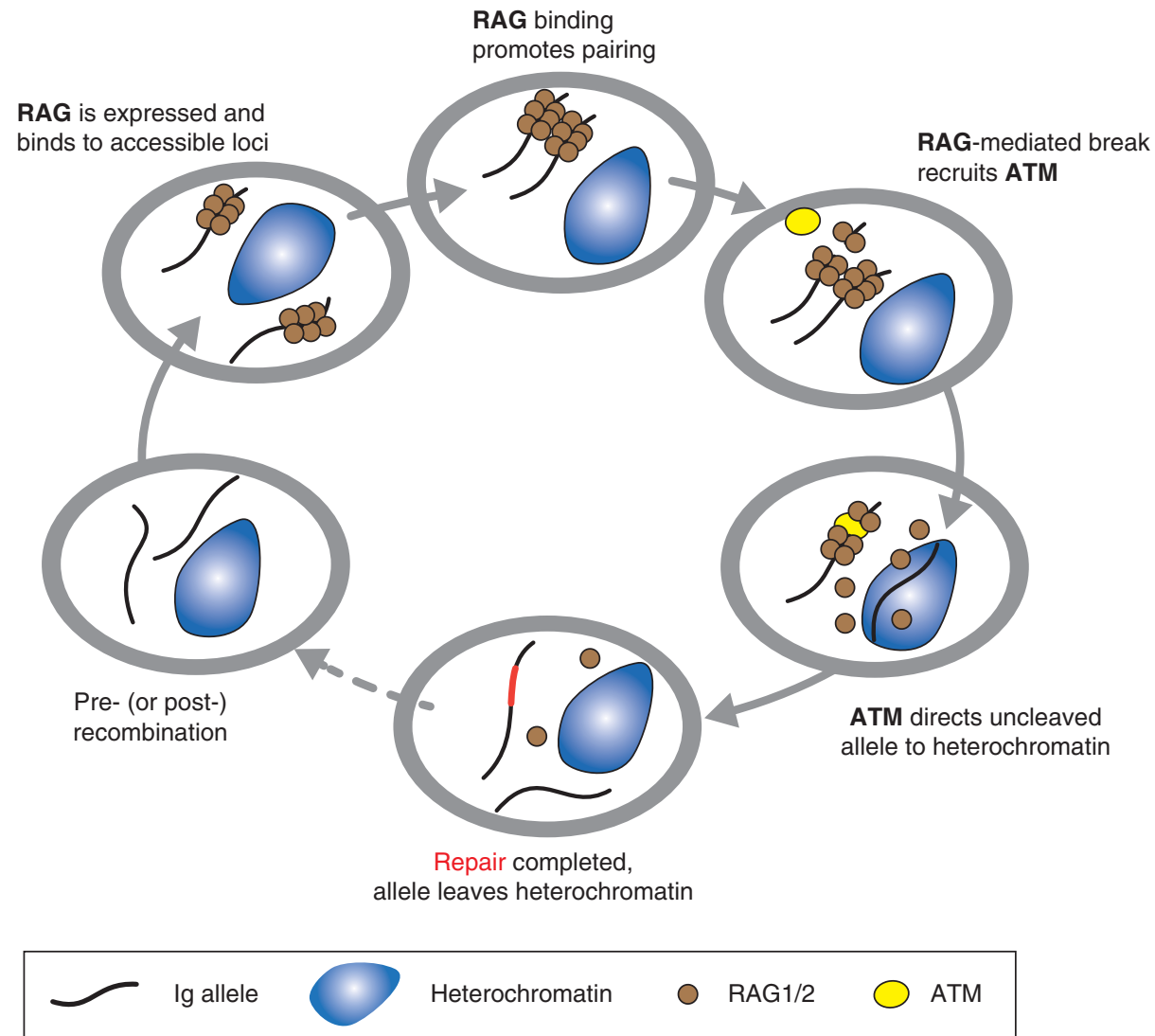

B

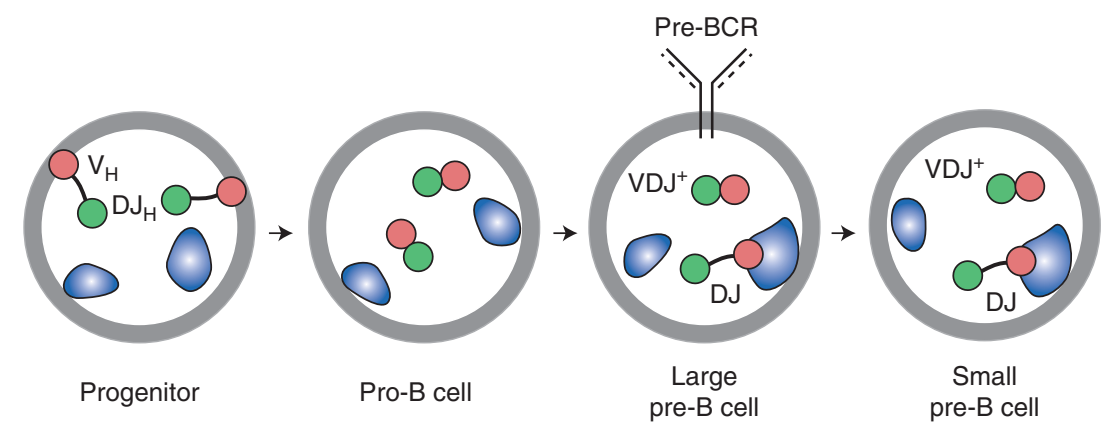

Figure 5. Control of monoallelic V(D)J recombination and subnuclear location of the $I g H$ locus in early B-cell development. (A) Control of monoallelic V(D)J recombination by pairing of $I g H$ alleles. See Chapter 4.2 for detailed explanation of the model describing the regulation of $\mathrm{V}(\mathrm{D}) \mathrm{J}$ recombination at the $I g H$ locus (black line) by the RAG1/2 endonuclease (brown) and repair-checkpoint protein ATM (yellow). (B) Subnuclear location of the two $I g H$ alleles at different stages of early B-cell development. The distal $\mathrm{V}_{\mathrm{H}}$ region (red) and proximal $\mathrm{J}_{\mathrm{H}}-\mathrm{C}_{\mathrm{H}}$ domain (green) of the $\mathrm{IgH}$ locus are indicated together with their location relative to the repressive compartments at the nuclear periphery (gray) and pericentromeric heterochromatin (blue). The contraction and decontraction of the $\mathrm{IgH}$ alleles are schematically shown. 
ing of the RAG1/2 complex is essential for homologous pairing, which selects one of the two Ig alleles for RAGmediated cleavage (Fig. 5A). The introduction of a DNA break on the rearranging $I g$ allele activates the repair-checkpoint protein ATM that in turn provides a signal in trans for repositioning of the uncleaved $I g$ allele to pericentromeric heterochromatin (Fig. 5A) (Hewitt et al. 2009). The repositioned Ig allele is likely protected from RAG1/2 cleavage in this heterochromatic environment during the time at which the rearrangement on the second allele is completed and functionally tested. Hence, $\mathrm{V}(\mathrm{D}) \mathrm{J}$ recombination initiates on paired Ig chromosomes and proceeds in a monoallelic manner through cycles of pairing and separation of homologous Ig alleles until a productive rearrangement has been generated or the two Ig alleles have be exhausted, which leads to either further development or cell death, respectively.

\subsection{Subnuclear Relocation of Antigen Receptor Loci in Developing Lymphocytes}

The nuclear periphery and pericentromeric heterochromatin are two repressive compartments in the nucleus that are important for propagating the inactive state of genes (Deniaud and Bickmore 2009). Depending on their activity state, genes are repositioned between these repressive compartments and central nuclear positions that facilitate gene transcription. Interestingly, the $I g H$ and $I g \kappa$ loci are located in their default state at the nuclear periphery in all non-B cells including uncommitted lymphoid progenitors (Kosak et al. 2002). The $I g H$ locus is thereby anchored via distal $\mathrm{V}_{\mathrm{H}}$ genes at the nuclear periphery and is oriented with the proximal $\mathrm{IgH}$ domain toward the center of the nucleus, facilitating $\mathrm{D}_{\mathrm{H}}-\mathrm{J}_{\mathrm{H}}$ rearrangements in lymphoid progenitors (Fig. 5B) (Fuxa et al. 2004). An important step of IgH locus activation consists of relocation of $I g H$ and $I g \kappa$ loci from the nuclear periphery to more central positions within the nucleus at the onset of B-cell development (Fig. 5B) (Kosak et al. 2002). This subnuclear repositioning likely promotes chromatin opening and germline transcription, leading to proximal $\mathrm{V}_{\mathrm{H}}-\mathrm{DJ} \mathrm{J}_{\mathrm{H}}$ rearrangements.

Although both alleles of the IgH and Igא loci are repositioned to central nuclear positions in pro-B cells (Kosak et al. 2002; Fuxa et al. 2004), the two alleles behave differently at the next developmental stage in pre-B cells. Following successful $\mathrm{V}_{\mathrm{H}}-\mathrm{DJ} \mathrm{J}_{\mathrm{H}}$ rearrangement, pre-BCR signaling leads to repositioning of the incompletely rearranged $I g H$ allele to repressive pericentromeric heterochromatin, whereas the functionally rearranged $\mathrm{IgH}$ alleles remain in a central nuclear position consistent with its continuous expression in pre-B cells (Fig. 5B) (Roldán et al. 2005).
Notably, one of the two Ig $\kappa$ alleles is also recruited to pericentromeric heterochromatin in pre-B cells before rearrangement, which favors $\mathrm{V}_{\mathrm{K}}-\mathrm{J}_{\mathrm{K}}$ recombination on the second $I g \kappa$ allele located in euchromatic regions of the nucleus (Hewitt et al. 2008). Interestingly, pericentromeric recruitment of the nonfunctional $\mathrm{IgH}$ allele occurs via the distal $\mathrm{V}_{\mathrm{H}}$ gene region suggesting that the same DNA sequences are involved in the recruitment of the $\mathrm{IgH}$ locus to either the nuclear periphery or pericentromeric heterochromatin (Fig. 5B) (Roldán et al. 2005).

Surprisingly, the two alleles of the TCR $\beta$ locus show little change in their association with the nuclear periphery or pericentromeric heterochromatin during T-cell development (Skok et al. 2007; Schlimgen et al. 2008). The frequent and stochastic association of one TCR $\beta$ allele with either of the two repressive compartments is likely to inhibit $V(D) J$ recombination in $\mathrm{DN}$ pro- $\mathrm{T}$ cells and may thus promote $\mathrm{V}_{\beta}-\mathrm{DJ}_{\beta}$ rearrangements on the second TCR $\beta$ allele (Skok et al. 2007; Schlimgen et al. 2008), similar to the situation described above for the monoallelic recruitment of $I g \kappa$ to pericentromeric heterochromatin. In contrast, the $T C R \alpha / \delta$ locus shows little association with the nuclear periphery or pericentromeric heterochromatin in developing thymocytes consistent with the fact that this locus undergoes $T C R \delta$ or TCR $\alpha$ rearrangements on both alleles in DN and DP thymocytes, respectively (Skok et al. 2007; Schlimgen et al. 2008).

\subsection{Spatial Control of V(D)J Recombination by Locus Contraction}

All four antigen receptor loci have a large size ranging from $0.67 \mathrm{Mb}(T C R \beta)$ and $1.6 \mathrm{Mb}(T C R \alpha / \delta)$ to $3 \mathrm{Mb}$ (IgH and $I g \kappa)$ and show a complex organization with the $\mathrm{D}, \mathrm{J}$, and $\mathrm{C}$ gene segments constituting the $3^{\prime}$ domain of each locus (Fig. 4A) (Jhunjhunwala et al. 2009). Enhancers and promoters located within this proximal domain control local chromatin structure, germline transcription, and recombination of gene segments at the $3^{\prime}$ end of the locus (Perlot and Alt 2008; Jhunjhunwala et al. 2009). The largest part ( $>80 \%$ ) of the Ig and TCR loci is, however, devoted to the V gene cluster consisting of an array of 31 (TCR $\beta)$ to 200 $(\mathrm{IgH}) \mathrm{V}$ genes, whose chromatin accessibility and germline transcription is regulated independently of the proximal domain (Hawwari and Krangel 2005; Jhunjhunwala et al. 2009). Hence, antigen receptor loci can be viewed as consisting of two distinct entities, the proximal domain and the $\mathrm{V}$ gene region, that are separated by a large distance on linear DNA. This separation spatially restricts the $\mathrm{V}(\mathrm{D}) \mathrm{J}$ recombination process, because antigen receptor loci are present in an extended conformation in nonlymphoid cells and lymphoid progenitors, as revealed by 3D DNA-FISH 
analysis (Fig. 6A) (Kosak et al. 2002; Fuxa et al. 2004; Roldán et al. 2005; Skok et al. 2007). As first shown for the $I g H$ locus, both alleles undergo long-range contraction in committed pro- $\mathrm{B}$ cells, which juxtaposes distal $\mathrm{V}_{\mathrm{H}}$ genes next to the rearranged proximal $\mathrm{DJ}_{\mathrm{H}}$ domain, thus facilitating $\mathrm{V}_{\mathrm{H}^{-}}$ DJ $_{\mathrm{H}}$ rearrangements (Fig. 6A) (Kosak et al. 2002; Fuxa et al. 2004). The $\mathrm{V}_{\mathrm{H}}$ gene cluster thereby undergoes looping in such a way that the different $\mathrm{V}_{\mathrm{H}}$ genes can undergo recombination at similar frequency, which is essential for the generation of a highly diverse immunoglobulin repertoire (Roldán et al. 2005; Sayegh et al. 2005; Jhunjhunwala et al. 2008; Medvedovic et al. 2013). Following successful $\mathrm{V}_{\mathrm{H}^{-}}$ $\mathrm{DJ}_{\mathrm{H}}$ recombination, pre-BCR signaling leads to decontraction of the nonfunctional $\mathrm{IgH}$ allele at the next develop-
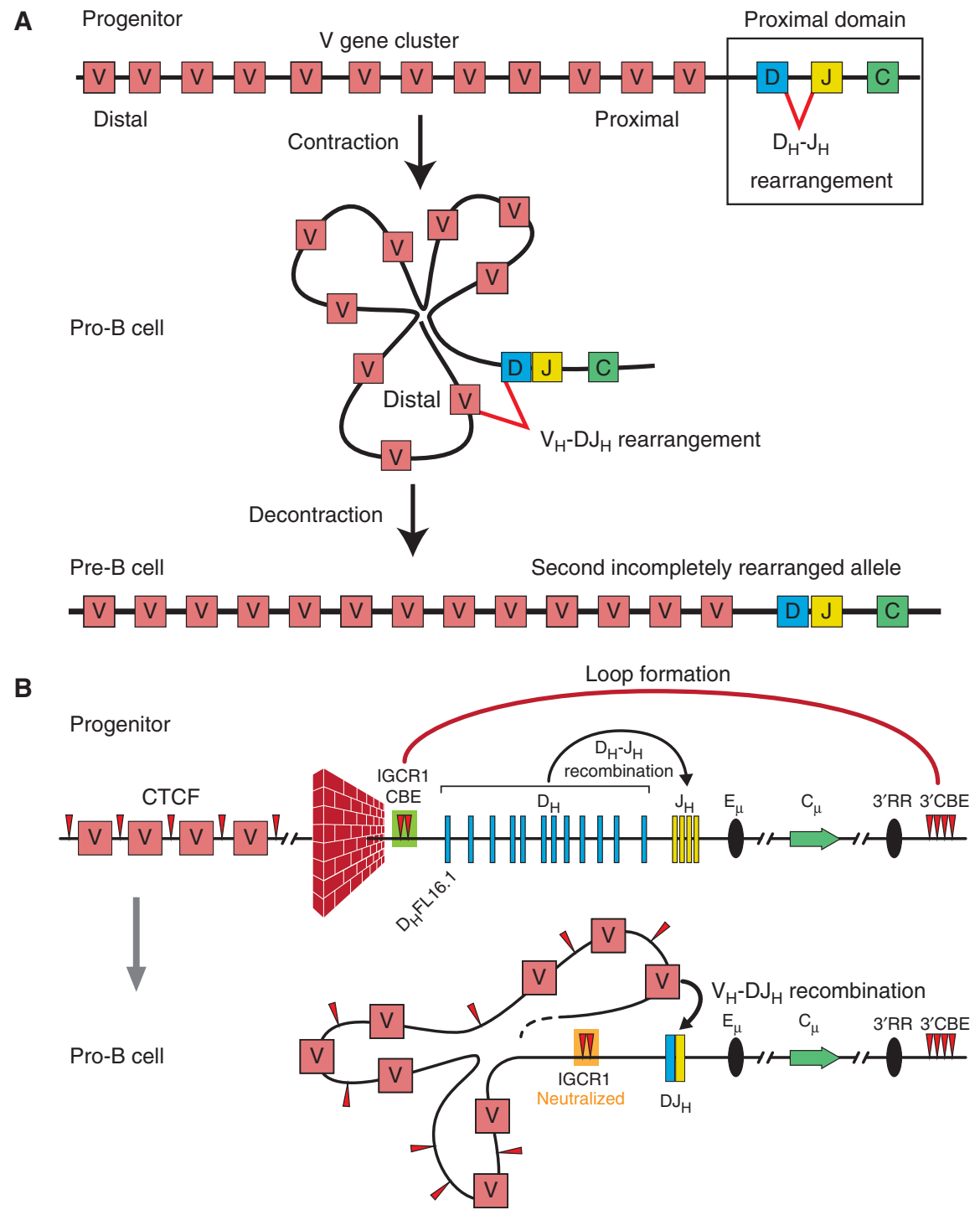

Figure 6. Spatial regulation and IGCR1-mediated control of $I g H$ recombination in early B-lymphopoiesis. $(A)$ Reversible $I g H$ contraction. The $I g H$ locus is in an extended configuration in uncommitted progenitors, which allows $\mathrm{D}_{\mathrm{H}^{-}} \mathrm{J}_{\mathrm{H}}$ recombination to take place in the proximal domain. In pro-B cells, all $200 \mathrm{~V}_{\mathrm{H}}$ genes participate in $\mathrm{V}_{\mathrm{H}}-\mathrm{DJ}_{\mathrm{H}}$ rearrangements because of contraction of the $I g H$ locus by looping. The $\mathrm{V}_{\mathrm{H}}$ genes of the incompletely rearranged $\mathrm{IgH}$ allele are no longer available for $\mathrm{V}_{\mathrm{H}}-\mathrm{DJ} \mathrm{H}_{\mathrm{H}}$ recombination because of decontraction in pre-B cells. $(B)$ Control of $\mathrm{IgH}$ recombination by the IGCR1 insulator. See Chapter 4.6 for detailed description how the IGCR1 region controls the order of $\mathrm{V}(\mathrm{D}) \mathrm{J}$ recombination at the $\mathrm{IgH}$ locus. CTCF-binding regions (CBEs) are symbolized by red arrowheads. A brick wall indicates that the IGCR1 insulator restrains loop formation and recombination to the proximal $\mathrm{IgH}$ domain in uncommitted lymphoid progenitors. In pro-B cells, the IGCR1 element is neutralized by a so-far unknown mechanism, and locus contraction promotes $\mathrm{V}_{\mathrm{H}}-\mathrm{DJ} \mathrm{H}_{\mathrm{H}}$ rearrangements. $3^{\prime} \mathrm{RR}, 3^{\prime}$ regulatory region; $\mathrm{E}_{\mu}$, intronic enhancer. 
mental stage that physically separates the distal $\mathrm{V}_{\mathrm{H}}$ genes from the proximal $\mathrm{IgH}$ domain, thus preventing further rearrangement of the second $\mathrm{IgH}$ allele in pre-B cells (Fig. 6A) (Roldán et al. 2005). Decontraction of the nonfunctional $\mathrm{IgH}$ allele occurs at the pericentromeric heterochromatin, where the $I g H$ allele is recruited in pre-B cells by interchromosomal pairing with the pericentromerically located $I g \kappa$ allele in a manner that depends on the $3^{\prime} I g \kappa$ enhancer (Fig. 5B) (Hewitt et al. 2008). All other antigen receptor loci $(I g \kappa, T C R \beta$, and $T C R \alpha / \delta)$ also show reversible contraction at the developmental stage, during which they undergo $\mathrm{V}(\mathrm{D}) \mathrm{J}$ recombination (Roldán et al. 2005; Skok et al. 2007). Hence, reversible locus contraction by looping is a general mechanism that promotes the spatial communication between $\mathrm{V}$ genes and the proximal domain and thus allows $\mathrm{V}$ genes to participate in $\mathrm{V}(\mathrm{D}) \mathrm{J}$ recombination. On the other hand, decontraction prevents further recombination at the next developmental stage and thereby contributes to the maintenance of allelic exclusion, which ensures the productive rearrangement of only one of the two antigen receptor loci.

To date, only a few trans-acting factors and cis-regulatory elements have been implicated in the control of locus contraction. Pax5 was identified as the first transcription factor to be involved in the pro-B-cell-specific contraction of the $I g H$ locus (Fuxa et al. 2004). In its absence, only the four most proximal of the $200 \mathrm{~V}_{\mathrm{H}}$ genes can efficiently undergo $\mathrm{V}_{\mathrm{H}}-\mathrm{DJ} \mathrm{J}_{\mathrm{H}}$ recombination, despite the fact that all $\mathrm{V}_{\mathrm{H}}$ genes are accessible and give rise to germline transcripts in Pax5-deficient pro-B cells (Hesslein et al. 2003; Roldán et al. 2005). A similar $\mathrm{V}_{\mathrm{H}}-\mathrm{DJ} \mathrm{H}_{\mathrm{H}}$ recombination phenotype was observed in pro-B cells lacking the histone methyltransferase Ezh2, an essential component of PRC2 that implies a critical role of this Polycomb complex in the regulation of IgH locus contraction (Su et al. 2003; A Ebert et al., pers. comm.). In addition to these two regulators, contraction of the $\mathrm{IgH}$ locus also depends on the ubiquitous transcription factor YY1 (Liu et al. 2007). Another potential regulator is the CCCTC-binding factor (CTCF) that has been implicated, through its association with cohesin, in long-range chromatin looping at several complex loci (Splinter et al. 2006; Hadjur et al. 2009; Nativio et al. 2009). CTCF and cohesin bind together to multiple sites along the $\mathrm{V}_{\mathrm{H}}$ gene cluster of the IgH locus (Degner et al. 2011; Ebert et al. 2011), and short hairpin RNA (shRNA) knockdown experiments have suggested a role for the CTCF/cohesin complex in the regulation of looping at the $\mathrm{IgH}$ locus in pro-B cells (Degner et al. 2011).

A systematic search for intergenic regions with active chromatin has recently identified 14 Pax5-activated intergenic repeat (PAIR) elements in the distal $\mathrm{V}_{\mathrm{H}}$ gene region of the IgH locus (Ebert et al. 2011). These PAIR elements are bound by Pax5, E2A, CTCF, and cohesin, carry Pax5-dependent active chromatin, and give rise to Pax5-regulated noncoding antisense transcripts exclusively in pro-B cells (Ebert et al. 2011). The pro-B-cell-specific and Pax5-dependent activity implicates the PAIR elements in the regulation of distal $\mathrm{V}_{\mathrm{H}}-\mathrm{DJ} \mathrm{H}_{\mathrm{H}}$ recombination, possibly by inducing IgH locus contraction (Ebert et al. 2011).

\subsection{Control of Ordered V(D)J Recombination by CTCF and Cohesin}

The transcription factor CTCF has been implicated not only in chromosome looping but in chromatin boundary formation, transcriptional insulation, activation, or repression (Phillips and Corces 2009). A large array of regularly spaced CTCF-binding sites characterizes the $\mathrm{V}$ gene clusters of all antigen receptor loci, whereas the proximal domains contain CTCF-binding sites only at their $5^{\prime}$ and $3^{\prime}$ boundaries (Degner et al. 2011; Ebert et al. 2011; Ribeiro de Almeida et al. 2011). The 100-kb region separating the $D_{H}$ and $\mathrm{V}_{\mathrm{H}}$ genes of the IgH locus contains two CTCF-binding elements (CBEs) located $2 \mathrm{~kb}$ upstream of the $\mathrm{D}_{\mathrm{H}} \mathrm{FL} 16.1$ gene segment at the $5^{\prime}$ end of the proximal $\mathrm{IgH}$ domain (Fig. 6B). Specific mutation of the two CTCF-binding sites within the so-called intergenic control region 1 (IGCR1) revealed that these two sites function as insulator elements to regulate ordered and lineage-specific $\mathrm{V}(\mathrm{D}) \mathrm{J}$ recombination at the IgH locus (Fig. 6B) (Guo et al. 2011). In uncommitted lymphoid progenitors, the IGCR1/CBE insulator is thought to restrict the potent $\mathrm{E}_{\mu}$ enhancer activity and all other long-range interactions to the proximal domain, which generates a local chromatin architecture that promotes $\mathrm{D}_{\mathrm{H}^{-}} \mathrm{J}_{\mathrm{H}}$ recombination on both $I g H$ alleles (Fig. 6B) (Guo et al. 2011). During normal development, the IGCR1/CBE insulator is only neutralized in committed pro-B cells possibly by Pax5-dependent contraction of the $I g H$ locus that facilitates $\mathrm{V}_{\mathrm{H}}-\mathrm{D} \mathrm{J}_{\mathrm{H}}$ recombination (Fig. $6 \mathrm{~B})$. In IGCR1/CBE mutant mice, the activity of the $\mathrm{E}_{\mu}$ enhancer is, however, no longer restrained and thus induces active chromatin and germline transcription at the first few proximal $\mathrm{V}_{\mathrm{H}}$ genes that undergo premature $\mathrm{V}_{\mathrm{H}}-\mathrm{DJ} \mathrm{H}_{\mathrm{H}}$ and even $\mathrm{V}_{\mathrm{H}}-\mathrm{D}_{\mathrm{H}}$ recombination in lymphoid progenitors and developing thymocytes (Guo et al. 2011). As a consequence of the precocious $\mathrm{V}_{\mathrm{H}}$ gene activity in lymphoid progenitors, fewer $\mathrm{DJ}_{\mathrm{H}^{-}}$-rearranged $I g H$ alleles are available for $\mathrm{V}_{\mathrm{H}^{-}}$ $\mathrm{DJ}_{\mathrm{H}}$ recombination at the next developmental stage in committed pro-B cells, which leads to a strong increase of proximal $\mathrm{V}_{\mathrm{H}}$ gene rearrangements and a corresponding skewing of the immunoglobulin repertoire. Hence, the CTCF-regulated IGCR1 activity and Pax5-mediated locus contraction fulfill opposing roles by preventing or promoting the participation of $\mathrm{V}_{\mathrm{H}}$ genes in $\mathrm{V}(\mathrm{D}) \mathrm{J}$ recom- 
bination in lymphoid progenitors or committed pro-B cells, respectively.

Similar to the $I g H$ locus, the intergenic $\mathrm{V}_{\mathrm{K}^{-}} \mathrm{J}_{\mathrm{K}}$ region of the $I g \kappa$ locus also contains a regulatory element (known as Sis) that functions as a silencer of recombination through binding of the transcription factors CTCF and Ikaros (Liu et al. 2006; Ribeiro de Almeida et al. 2011). Deletion of the Sis element or conditional inactivation of CTCF similarly affect $\mathrm{V}_{\mathrm{K}}-\mathrm{J}_{\mathrm{K}}$ rearrangements in pre-B cells by increasing germline transcription and recombination of proximal $V_{K}$ genes at the expense of distal $V_{\kappa}$ gene recombination (Ribeiro de Almeida et al. 2011; Xiang et al. 2011). The loss of CTCF thereby skews the repertoire of $\mathrm{V}_{\mathrm{K}}-\mathrm{J}_{\mathrm{K}}$ rearrangements by strongly increasing the interactions of the iEK and $3^{\prime}$ Eк enhancers with proximal $V_{\kappa}$ genes (Ribeiro de Almeida et al. 2011). This evidence suggests that the Sis element functions as an insulator to negatively regulate proximal $V_{\mathrm{K}}$ gene recombination by blocking the long-range activity of Igк enhancers (Ribeiro de Almeida et al. 2011) similar to the role of the IGCR1 element in the control of $I g H$ rearrangements (Guo et al. 2011). CTCF binds together with cohesin to both regulatory regions (Ebert et al. 2011), indicating that cohesin may mediate the enhancer-blocking function of CTCF at these elements. In support of such a hypothesis, conditional loss of the cohesin subunit $\operatorname{Rad} 21$ impairs TCR $\alpha$ rearrangements in DP thymocytes by affecting the histone modification and transcription patterns in the proximal TCR $\alpha$ domain due to altered long-range interactions of the $\mathrm{E}_{\alpha}$ enhancer (Seitan et al. 2011).

\section{ROLE OF EPIGENETIC REGULATORS IN LYMPHOID MALIGNANCIES}

High-resolution genomic analyses of single-nucleotide polymorphisms and genome-wide DNA and RNA sequencing have provided fascinating new insight into the genetic basis of leukemia and lymphoma development. As shown by these global analyses, the majority of mutations detected in lymphoid malignancies affect the function of hematopoietic transcription factors and epigenetic regulators in addition to the signaling of cytokine and antigen receptors (Mullighan et al. 2007; Morin et al. 2011; Zhang et al. 2012a). Among the different classes of epigenetic regulators, several writers (CREBBP, EP300, MLL1, MLL2, PRC2, MMSET, and SETD2) and one eraser (UTX) are frequently mutated in lymphoid malignancies (Fig. 7), whereas genetic alterations affecting readers have so far not been reported. The highly related lysine acetyltransferases CREBBP (CBP) and EP300 (p300) are known to function as coactivators for a large number of DNAbinding transcription factors by modifying histone and nonhistone nuclear proteins (Ogryzko et al. 1996). Mono-

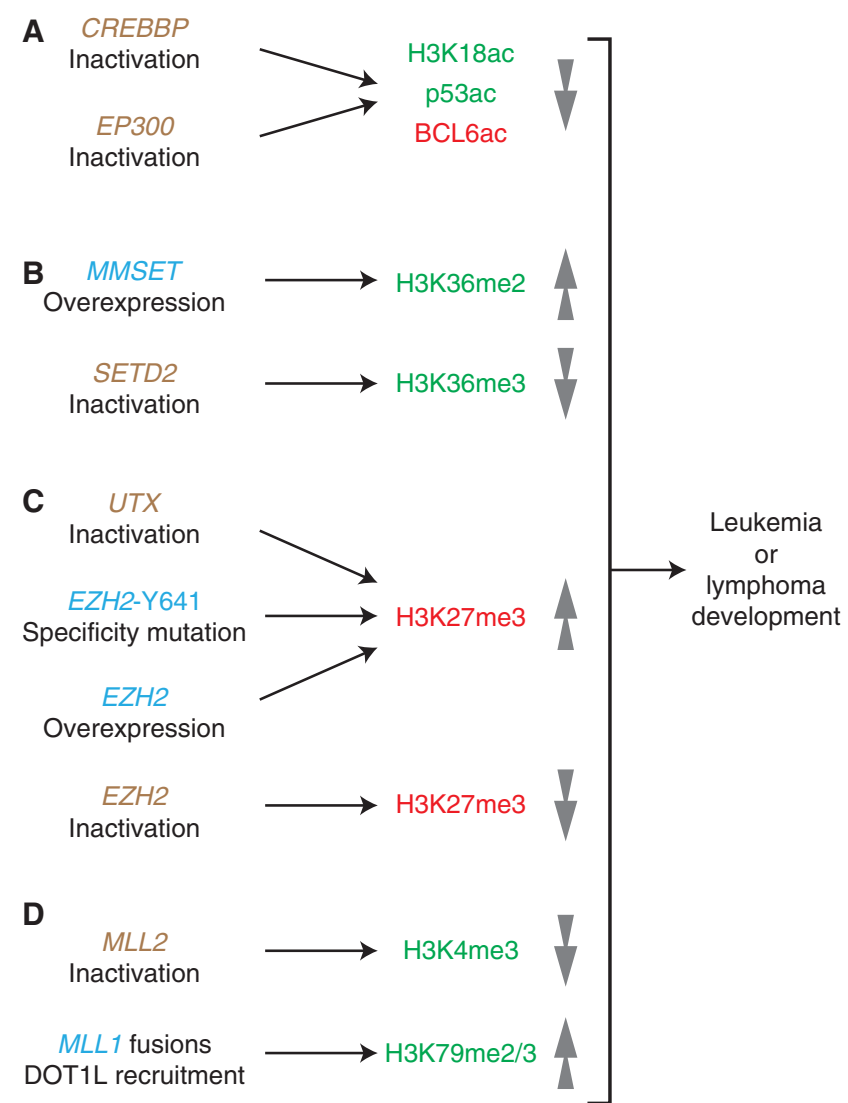

Figure 7. Role of histone-modifying enzymes in leukemia and lymphoma. (A) Monoallelic mutation of the CREBBP (CBP) or EP300 (p300) gene results in reduced acetylation of BCL6, p53, and histone $\mathrm{H} 3$ in B-cell lymphoma. (B) Overexpression of the H3K36 dimethylase MMSET (NSD2, WHSC1) in multiple myeloma and loss of the H3K36 trimethylase SETD2 in early T-cell precursor acute lymphoblastic leukemia (ETP-ALL) contribute to tumorigenesis by altering the methylation state of lysine 36 of histone H3. (C) Loss of the H3K27 demethylase UTX as well as an altered specificity mutation and overexpression of the H3K27 methyltransferase EZH2 are implicated in the formation of B-cell malignancies by increasing the abundance of the repressive histone mark H3K27me3, whereas loss of EZH2 is associated with T-ALL. (D) Inactivation of the H3K4 methyltransferase MLL2 results in decreased levels of the active modification H3K4me3 in B-cell lymphoma, whereas MLL1 fusion proteins recruit the methyltransferase DOT1L to focally increase H3K79 methylation in MLL1-rearranged leukemias. The following color code is used: oncogenes (blue), tumor-suppressor genes (brown), active (green), and repressive (red) protein modifications.

allelic deletions or point mutations inactivate the CREBBP or EP300 gene in $41 \%$ of follicular lymphoma (FL), 39\% of diffuse large B-cell lymphoma (DLBCL), and 18\% of relapsed B-cell acute lymphoblastic leukemia (B-ALL), suggesting that the two acetyltransferases function as haploinsufficient tumor suppressors in these lymphoid malignancies (Mullighan et al. 2011; Pasqualucci et al. 2011). Notably, the mutant CREBBP and EP300 proteins are un- 
able to acetylate the transcription factors p53 and BCL6, which are both expressed in FL and DLBCL (Pasqualucci et al. 2011). The fact that acetylation activates the tumor suppressor p53 (Lill et al. 1997) and inactivates the oncoprotein BCL6 (Bereshchenko et al. 2002) suggests the following mechanism of action for the CREBBP or EP300 mutations. In addition to a general effect on histone acetylation $(\mathrm{H} 3 \mathrm{~K} 18 \mathrm{ac})$ and gene transcription (Mullighan et al. 2011), the decreased activity of CREBBP or EP300 may lead to increased BCL6 and decreased p53 activity, which favors enhanced tolerance of DNA damage (mediated by BCL6) at the expense of diminished apoptosis and cell cycle arrest (mediated by p53ac) in FL and DLBCL (Fig. 7A) (Pasqualucci et al. 2011). It may, therefore, be of clinical benefit to use already approved histone deacetylase inhibitors to restore physiological acetylation levels in tumors with CREBBP and EP300 mutations.

The histone methyltransferase MMSET (NSD2, WHSC1) is overexpressed in $15 \%-20 \%$ of the plasma-cell-derived tumor multiple myeloma ( $\mathrm{MM})$ as a consequence of the $\mathrm{t}(4 ; 14)(\mathrm{p} 16.3 ; \mathrm{q} 32)$ translocation that places the MMSET gene under the control of the $\mathrm{E}_{\mu}$ enhancer of the $\mathrm{IgH}$ locus (Keats et al. 2003). MMSET catalyzes H3K36 dimethylation, and its increased expression in $\mathrm{t}(4 ; 14)$-positive myeloma cells alters the genome-wide pattern of H3K36me2, which results in localized chromatin relaxation and expression of normally silent genes that promote plasma cell transformation (Fig. 7B) (Kuo et al. 2011). Consistent with this notion, ectopic expression of a wild-type but not of a catalytically dead MMSET protein in $\mathrm{t}(4 ; 14)$-negative myeloma cells rapidly induces tumor development in a mouse xenograft model, suggesting that MMSET is a potent oncoprotein (Kuo et al. 2011). Interestingly, the nonredundant methyltransferase SETD2, which mediates all H3K36 trimethylation (Edmunds et al. 2008), functions as a tumor suppressor, because its gene is inactivated by biallelic mutations in early T-cell precursor acute lymphoblastic leukemia (ETP-ALL), leading to a reduction of global H3K36me3 levels (Fig. 7B) (Zhang et al. 2012a). Hence, MMSET and SETD2 appear to have antagonistic functions in cancer development, which may reflect distinct functions of the H3K36 di- and trimethylation states in controlling gene expression.

PRC2 consists of the core components EED and SUZ12 and the methyltransferase EZH2 that mediates gene silencing by methylating histone $\mathrm{H} 3$ at lysine 27. EED, SUZ12, or $E Z H 2$ are mutated by deletions or inactivating point mutations in $42 \%$ of ETP-ALL and $25 \%$ of T-ALL (Fig. 7C) (Ntziachristos et al. 2012; Zhang et al. 2012a). Some of these mutations are even homozygous, further indicating a tumor-suppressing function of PRC2 in T-ALL (Ntziachristos et al. 2012). In support of this finding, T-cell leukemia arises at a high frequency in mice undergoing conditional Ezh2 inactivation in HSCs (Simon et al. 2012). Notably, genetic alterations of $P R C 2$ are frequently associated with NOTCH1 mutations suggesting that the loss of the repressive H3K27me3 mark cooperates with constitutively active $\mathrm{NOTCH} 1$ in inducing an oncogenic gene expression program in T-ALL (Ntziachristos et al. 2012).

Mutations of EZH2 are also found in 22\% of germinalcenter B-cell-like DLBCL and 7\% of FL (Morin et al. 2010). Surprisingly, however, all heterozygous mutations result in the replacement of a single tyrosine residue (Y641) in the catalytic site of the SET domain of EZH2 (Morin et al. 2010). Detailed biochemical analysis revealed that the wild-type EZH2 enzyme displays greatest catalytic activity for the H3K27 monomethylation reaction, but diminished activity for the subsequent di- and trimethylation steps (Sneeringer et al. 2010). Importantly, all amino acid replacements at Y641 result in an altered substrate specificity of the mutant EZH2 protein, which has limited ability to perform the first methylation reaction but displays enhanced catalytic activity for the subsequent methylation steps (Sneeringer et al. 2010). This change in substrate specificity is caused by the enlarged active site of the mutant EZH2 protein, which favors di- and trimethylation but interferes with the first methyl transfer reaction. The coexpression of wild-type and mutant EZH2 proteins consequently leads to coupling of the enzymatic activities between the H3K27-monomethylating wild-type enzyme and the efficiently di- and trimethylating mutant enzyme, which results in substantially increased H3K27me3 levels in lymphoma cells (Fig. 7C) (Sneeringer et al. 2010; Yap et al. 2011). Hence, the Y641 substitutions of EZH2 are oncogenic gain-of-function mutations that increase $\mathrm{H} 3 \mathrm{~K} 27$ trimethylation and thus enhance gene silencing similar to the previously reported overexpression of EZH2 in B-cell lymphoma (Bracken et al. 2003). Interestingly, the X-linked gene coding for the H3K27 demethylase UTX is frequently mutated in human cancer including multiple myeloma and B-ALL, which leads to increased H3K27me3 levels and cell proliferation (Fig. 7C) (van Haaften et al. 2009; Mar et al. 2012). In summary, the Y641 mutation and overexpression of EZH2, as well as the loss of UTX, affect the same epigenetic pathway by increasing $\mathrm{H} 3 \mathrm{~K} 27$ trimethylation and gene repression in tumor cells (Fig. 7C).

The Trithorax group protein MLL2 is one of six human methyltransferases that generate the active $\mathrm{H} 3 \mathrm{~K} 4 \mathrm{me} 3$ mark at promoters of transcribed genes. Notably, MLL2 is one of the most frequently mutated genes in FL (89\%) and DLBCL (32\%; Morin et al. 2011). The majority of these mutations are heterozygous and truncate the large MLL2 protein, thus identifying this methyltransferase as a prominent tumor suppressor in B-cell non-Hodgkin's lympho- 
ma (Morin et al. 2011). Hence, the partial loss of the activating MLL2 protein contributes to tumor development by decreasing the active $\mathrm{H} 3 \mathrm{~K} 4 \mathrm{me} 3$ mark, thus reducing expression of key genes in B-cell lymphoma (Fig. 7D).

Approximately $50 \%$ of infant ALLs and $\sim 10 \%$ of adult leukemias are characterized by the presence of MLL1 translocations that code for fusion proteins with potent leukemia-inducing activity (Liu et al. 2009). MLL1, like MLL2, is also a large multidomain protein containing the H3K4methylating SET domain at the very carboxyl terminus. MLL1 translocations generate fusion proteins consisting of the amino-terminal third of MLL1 linked to different carboxy-terminal partner proteins (Liu et al. 2009). Although 71 distinct fusion partners are known to date, the majority of MLL1-rearranged leukemias express fusion proteins involving the partners AF4, AF9, AF10, AFF4, ENL, or ELL1, all of which are components of the super elongation complex regulating transcription elongation by RNA polymerase II (RNA Pol II) (Luo et al. 2012). Hence, these MLL fusions proteins have been implicated in leukemia development by deregulating transcription elongation. In addition to this mechanism, the AF4, AF9, AF10, and ENL partner proteins also interact with DOT1L, which methylates lysine 79 in the globular domain of histone H3 (Okada et al. 2005; Luo et al. 2012). These MLL fusion proteins immortalize leukemic cells only in the presence of a functional DOT1L methyltransferase (Okada et al. 2005), leading to increased H3K79 methylation and transcription at gene loci coding for developmental regulators (Fig. 7D) (Guenther et al. 2008).

\section{CHROMATIN-MEDIATED CONTROL OF THE INFLAMMATORY RESPONSE}

\subsection{Transcriptional Dynamics of the Inflammatory Response}

Inflammation is the human or animal response to infection or tissue damage. Similar to cognitive and metabolic processes, inflammation is essential for the adaptation of the organism to the environment and maintenance of the body's homeostasis (Medzhitov 2008). The inflammatory response is largely mediated by myeloid lineage cells that either migrate (neutrophils and monocytes) or reside steadily in the tissue (Kuppfer cells in liver or microglia cells in the brain). Epigenetic mechanisms that cooperate with transcriptional control, discussed in this section, play a significant role in effecting and regulating the inflammatory response in macrophages, but are likely to represent a common mechanism that operates in various cell types.

One of the common hallmarks of inflammation is a temporal reprofiling of gene expression patterns in affected cells (Zak and Aderem 2009; Smale 2010b). Indeed, exposure of cells to inflammatory signals modulates transcription of several hundreds of genes, including those that enable the whole body awareness of a local inflammatory state (Gilchrist et al. 2006; Medzhitov and Horng 2009; Smale 2010b; Bhatt et al. 2012). The elaborate dissection of the transcriptional response associated with inflammation has been performed on in vitro cultured macrophages treated with Gram-negative bacteria-derived lipopolysaccharide (LPS) or its active component lipid A (Fig. 8) (Ramirez-Carrozzi et al. 2009; Bhatt et al. 2012). LPS-activated genes can be divided into several major groups based on their timing of expression and the biochemical nature of the encoded protein. Analysis of the chromatin-bound and cytosolic RNA transcripts was performed in lipid A-triggered bone-marrow-derived macrophages. This showed up-regulation of gene transcription as early as 15 min after stimulation (16 genes) followed by activation of hundreds of genes in the course of a 2-h period after stimulation (Bhatt et al. 2012). The degree of gene up-regulation varied significantly among individual loci: 246 genes were induced five- and 10-fold, 247 between 10- and 100-fold, and $67>100$-fold.

A common theme that has emerged from studies of LPS-inducible genes is a connection between timing of gene expression and the epigenetic state of the inducible gene. In particular, the different temporal patterns of gene expression, in response to LPS, appear to be embedded within the $\mathrm{CpG}$ content of inducible gene promoters (Ramirez-Carrozzi et al. 2009; Smale 2010b; Natoli et al. 2011; Bhatt et al. 2012; see Li and Zhang 2014 for details on $\mathrm{CpG}$ islands). In macrophages, promoters rich in $\mathrm{CpG}$ islands are highly prevalent among so-called primary and weakly induced secondary response genes. CpG-low promoters, however, are more prevalent among secondary response genes that are induced at a higher level (Fig. 9) (Ramirez-Carrozzi et al. 2009; Bhatt et al. 2012). In both primary and secondary response genes, $\mathrm{CpG}$ abundance correlates with the presence of chromatin marks that are commonly associated with either ongoing gene transcription typical of actively transcribed genes or those with a predisposition to rapid gene activation in response to stimuli. Rapidly activated genes with a mostly high CpG content, described as poised, are common among stressresponse genes (Adelman and Lis 2012). They are characterized by gene promoters with a relatively high abundance of RNA Pol II and methylated histone $\mathrm{H} 3$ at lysine 4 (H3K4me3; see primary and weakly induced secondary response genes in Fig. 9) (Gilchrist and Adelman 2012; Kwak et al. 2013).

Low CpG content at promoters stabilizes nucleosome formation. This explains why CpG-low genes (i.e., strongly 


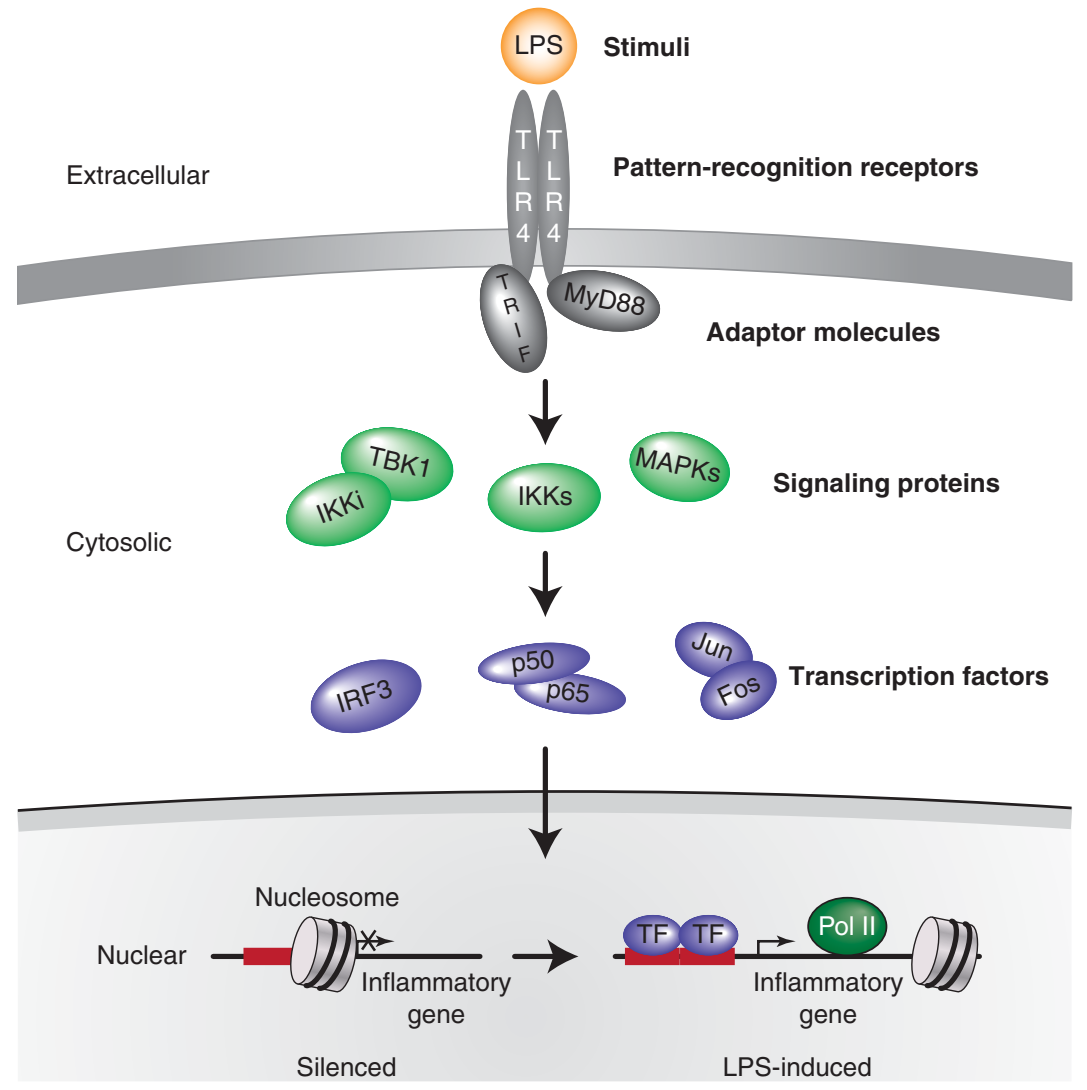

Figure 8. Signaling control of LPS-induced gene expression. The Gram-negative bacteria-derived LPS binds to the surface-expressed Toll-like receptor 4 (TLR4). Binding to TLR4 leads to activation of cytosolic signaling proteins and ensuing activation of diverse transcription factors such as NF- $\mathrm{BB}$ ( $\mathrm{p} 50 / \mathrm{p} 65)$ and AP-1 (Jun/Fos). Transcription factors enter the cell nucleus and bind to the promoters of proinflammatory genes. In numerous cases, binding of transcription factors requires prior chromatin remodeling that provides transcription factor access to the otherwise nucleosome-occluded regulatory regions.

induced secondary response genes) strongly depend on chromatin remodeling for their activation (Ramirez-Carrozzi et al. 2009). Thus, LPS-induced inflammatory genes with CpG-low promoters can be viewed as examples of covered promoters (Lam et al. 2008; Cairns 2009; Bai and Morozov 2010). They are considered covered when nucleosomes occlude the transcriptional start site (TSS), the regions flanking the TSS, and most of the binding sites for transcriptional activators (Fig. 9) (Lam et al. 2008; Cairns 2009). At covered promoters, nucleosomes compete effectively with transcription factors for occupancy of key cis-regulatory binding sites, rendering covered promoters more reliant on chromatin remodeling and modifying enzymes to help "uncover" cis-regulatory sites and allow activity (Bai et al. 2011). In addition to the dependence on chromatin remodelers, the activation of genes controlled by covered promoters may require pioneer factors that bind to linker DNA among nucleosomes or directly to nucleosomes and facilitate accompanying chromatin remodeling
(Smale 2010a). In the context of inflammation, one can predict that the combination of high- and low-affinitybinding sites for specific transcriptional regulators as well as the differences in promoter occlusion by nucleosomes help to adjust inflammatory response genes to signals of various types and strengths.

The differences in chromatin architecture between primary and secondary response genes are likely to yield differences in gene dynamics. Studies of gene dynamics in prokaryotic and eukaryotic cells has described the discontinuous nature of gene transcription occurring through bursts of activity (gene "on"), in which many messenger RNAs (mRNAs) are transcribed and interspersed with periods of inactivity (gene "off") (Fig. 10A) (Cai et al. 2008; Pedraza and Paulsson 2008; Chubb and Liverpool 2010; Larson 2011). The duration of transcriptional bursts, the size of the bursts, and the interval separating the bursts vary from a few minutes to many hours (Larson 2011; Yosef and Regev 2011). The "burstiness" of individual genes and duration of 

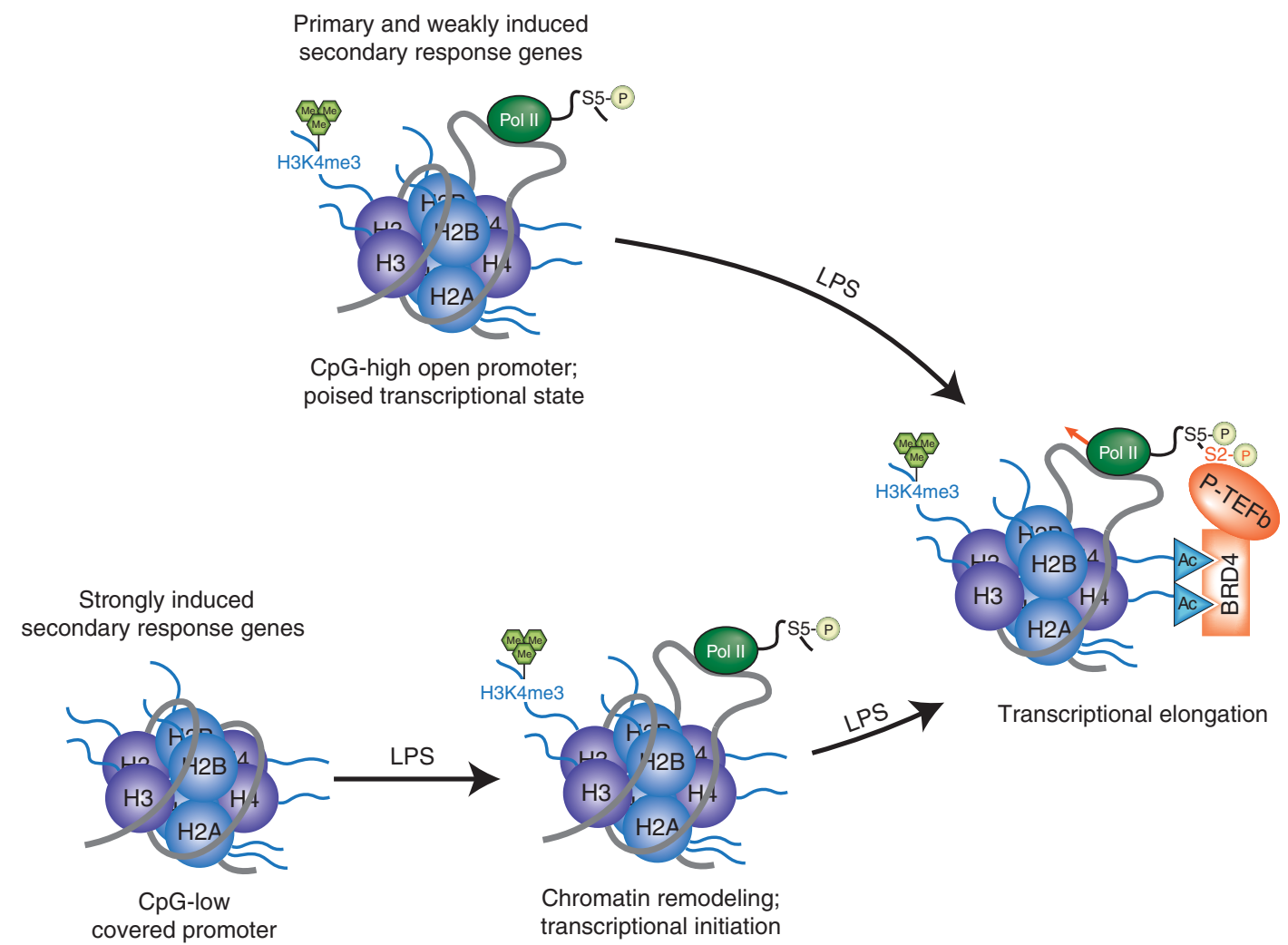

Figure 9. Chromatin-mediated control of the temporal pattern of proinflammatory gene expression. Key features of chromatin associated with LPS-induced genes are shown. The emphasis is placed on the differences in the CpG content of the differentially induced gene promoters as well as the abundance of the chromatin mark $\mathrm{H} 3 \mathrm{~K} 4 \mathrm{~m} 3$ and serine 5-phosphorylated RNA Pol II, which is characteristic for the poised state of gene expression. In both the primary and secondary response genes, RNA elongation is supported by binding of BRD4 to acetylated histone H4. The histone-bound BRD4 recruits P-TEFb, which governs an initial phase of the RNA elongation process.

the refractory phase depend on the state of the chromatin and the local concentration of transcription factors (Raj and van Oudenaarden 2009). In such a model, referred to as the promoter progression model, changes in nucleosome occupancy occur at a slow rate (minutes to hours), but once the promoter is open, the transcription machinery will assemble rapidly (in seconds or less) and trigger the "burst" that will continue as long as RNA Pol II is supplied and used by the RNA elongating machinery (Larson 2011).

According to the promoter progression model (Larson 2011), one can expect a direct correlation between the number of steps that are required for gene activation and the duration of the refractory state (i.e., bursty behavior) during inflammatory responses. Secondary response genes are likely to have a limited number of activation cycles, thus limiting the production of inflammatory triggers that can propagate the inflammatory process even in the absence of the initial stimulus.

The discontinuous pattern of gene regulation may contribute not only to timing of gene expression during initial cell response to the proinflammatory signals, but also during cell responses to repetitive triggering. Some initially activated cells fail to be reactivated by LPS (termed tolerance), as judged by the inability of "tolerant" cells to express numerous inflammatory triggers, including cytokines such as IL-6 or IL-12 (Foster et al. 2007; Medzhitov and Horng 2009). However, certain genes, including those that encode secreted antimicrobial peptides, escape tolerance induction (Foster et al 2007). Studies by Medzhitov's group show that, after stimulation of naïve macrophages with LPS, RNA Pol II was recruited equally well to promoters of tolerizable and nontolerizable genes (Foster et al. 2007). Tolerance to LPS selectively affects RNA Pol II recruitment to the tolerizable genes after secondary LPS triggering. Although promoters of both tolerizable and nontolerizable genes were initially acetylated at histone $\mathrm{H} 4$ after the first instance of macrophage activation, only histones at nontolerizable gene promoters were reacetylated after LPS stimulation of tolerant macrophages. Tolerizable 
A

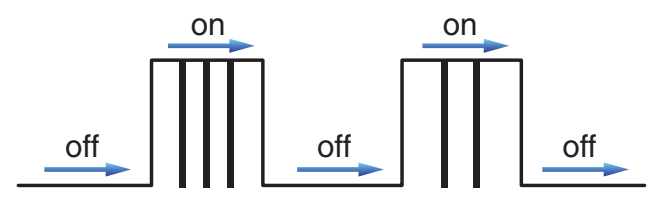

B

B Digital response genes (typical of primary response genes)

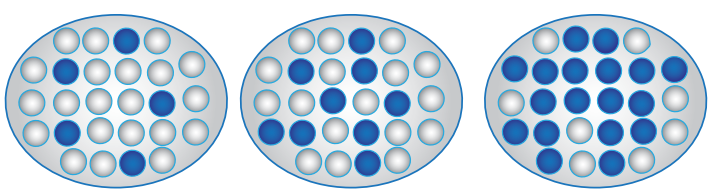

C

Analog response genes (typical of secondary response genes)

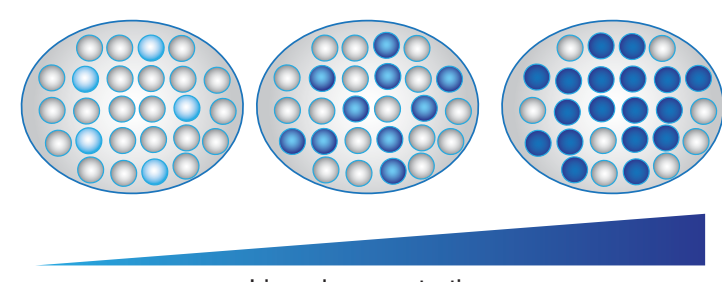

Ligand concentration

Figure 10. Dynamic control of gene expression. (A) Oscillatory dynamics of gene expression. The transition from the silent to active state is shown in a two-dimensional fashion. The rectangle represents the phase of active gene transcription and elongation (transcriptional burst), in which individual vertical bars indicate the number of transcripts generated during the burst. The transcriptional burst is followed by gene silencing. The amount of RNA transcripts produced per burst defines the size of the burst, and the number of bursts per defined time periods (from seconds to hours) corresponds to the burst frequency. $(B, C)$ Genes can be induced in a "digital" $(B)$ or "analog" $(C)$ fashion. The responding or nonresponding cells are shown as closed or open circles, respectively. The graded color of the closed circles reflects differences in gene expression levels.

genes appear to maintain the covered state of their promoters in the tolerant state.

The described dynamics of chromatin changes of nontolerizable and tolerizable genes, that do not correlate with primary and secondary gene expression during initial cell triggering by LPS, matches well the predictive behavior of genes with an extended "off" state of the transcriptional cycle. The duration of this cycle can be determined either by intrinsic factors (e.g., local gene environment) or by extrinsic factors (e.g., signaling and metabolic changes). Tolerance in macrophages is associated with expression of proteins that attenuate LPS signaling and, hence, reduce the overall extrinsic signaling input (Foster et al. 2007). The reduced signaling, although generic by nature, may have a selectively stronger impact on genes that depend critically on signaling for repetitive entry into the transcriptional cycle. As a consequence, these genes might display an extended refractory phase to a point in which cells will be perceived as unresponsive or tolerant.

By mentioning perception of a phenotype, we intentionally imply our currently limited ability to distinguish between population response and the response of individual cells. It is conceivable that stable production of antimicrobial peptides, as well as other nontolerizable genes in otherwise LPS-tolerant macrophages, may reflect the existence of a specialized or randomly appearing cell subpopulation in which stochastic arrangement of signaling proteins, metabolic enzymes, and transcription factors generate conditions that do not favor LPS tolerance. Support for intrapopulational diversity during inflammatory responses is offered by studies that show stochastic expression of various proinflammatory cytokines in responding cells. In brief, during viral infection, only a limited fraction of cells are able to activate type I interferon IFN $\beta$ gene expression (Zhao et al. 2012). The type I interferon, induced by bacterial and viral infection, plays a key role in antiviral host response. The low frequency of IFN $\beta$-expressing cells, as well as differentially triggered lymphoid cells expressing cytokines such as IL-2, IL-4, IL-10, IL-5, and IL-13 (Guo et al. 2004; Murphy 2005; Paixao et al. 2007), reflects the stochastic intercellular distribution of factors that contribute critically to cytokine expression but are expressed at too low levels to be distributed equally among the cells of a given population. Although the nature of limiting factors that control stochastic gene expression is not fully understood, the underlying mechanism of uneven gene expression is likely to rely on the chromatin architecture of stochastically expressed genes. The covered promoters have a much higher level of transcriptional variation as compared to genes controlled by open promoters (Bai and Morozov 2010). In addition, the presence of suppressive histone marks, such as $\mathrm{H} 3 \mathrm{~K} 9 \mathrm{me} 2$ and $\mathrm{H} 3 \mathrm{~K} 27 \mathrm{me}$, may create an additional barrier for activation of inflammatory genes and contribute to intra- and interpopulation differences in inflammatory gene expression (Saccani and Natoli 2002; De Santa et al. 2007; Fang et al. 2012). Although chromatin plays an important role in gene expression, there are other sources of variation in gene expression. Gene positioning within the nuclear space or gene "looping" could, for instance, contribute to the variability of gene expression among individual cells (de Wit and van Steensel 2009).

\subsection{Transcriptional Noise, Digital versus Analog Gene Regulation, and Diversity of the Immune Response}

The notion of individual differences in gene expression between cells involved in inflammation reverberates with 
a question about the sources and role of transcriptional diversity (transcriptional noise) during inflammation. Transcriptional noise refers to the variability in the expression of individual gene alleles in a cell population held under constant conditions (Blake et al. 2003; Raser and O'Shea 2005; Eldar and Elowitz 2010; Balazsi et al. 2011). The transcriptional noise could be either intrinsic, that is, governed by concentration of transcription factor(s) within a cell, or extrinsic and driven by environmental triggers. The major purpose of transcriptional noise is to adapt to changes in the environment (Balazsi et al. 2011). In yeast that have been engineered to transit randomly but at different switching rates between two phenotypes in response to stochastic fluctuations in gene expression, the environment stability had a strong influence on the dominance of a particular strain (Cairns 2009). When environmental conditions are stable, the strain with slower phenotypic transitions dominates the population, but when the environment fluctuates more quickly, faster transitions are beneficial. Similarly, microbial populations use phenotypic heterogeneity as a strategy to respond to unpredictable changes in the environment (Maheshri and O'Shea 2007; Eldar and Elowitz 2010).

The unpredictability of the environment best describes the situation that awaits migratory inflammatory cells, that is, neutrophils, lymphocytes, or monocytes. Therefore, one would predict a propensity for transcriptional noise in these cells at levels that will enable rapid population adaptation to different environmental settings. Kinetically static tissue cells such as hepatocytes or muscle cells, however, are likely to limit the noise to reduce the cell's responsiveness to random inflammatory signals. A mechanism that would significantly increase the noise of proinflammatory genes in hematopoietic cells but "de-noise" these genes in nonhematopoietic cells has thus provided the basis for investigations. Results in fibroblasts as well as in cardiac myocytes and neurons showed that the IFN- $\alpha / \beta$-stimulated genes (ISGs) and NF- $\mathrm{kB}$-inducible genes display enrichment in a suppressive $\mathrm{H} 3 \mathrm{~K} 9 \mathrm{me} 2$ mark at their promoters, whereas the same genes in macrophages and dendritic cells are largely H3K9me2-depleted (Fang et al. 2012). It is possible that $\mathrm{H} 3 \mathrm{~K} 9 \mathrm{me} 2$ as well as other suppressive modifications, that is, $\mathrm{H} 3 \mathrm{~K} 27 \mathrm{me}$, at the inflammatory genes may establish the level of transcriptional noise of inflammatory genes and determine the range of cell responsiveness to proinflammatory signals. In support of this model, removal of H3K9me2 from fibroblasts decreased the threshold for cell activation and allowed for virus-induced expression of IFN $-\alpha / \beta$ and interferon-stimulated genes at levels characteristic for "professional" IFN- $\alpha / \beta$-producing dendritic cells (Fang et al. 2012). One can speculate that factors that reduce the noise are likely to play a key role in protect- ing nonmigratory cells from erroneous inflammatory responses caused by minor tissue damage or metabolic stress. In turn, those factors that increase noise within migratory cells are likely to increase the probability of inflammatory responses during infection.

The probability of an initial transcriptional response to proinflammatory signals determines the scope or degree of population engagement into an inflammatory process. As discussed in Sec. 6.1, the dynamics of the initiation process is gene specific, in which collaboration among a gene sequence, chromatin state, intranuclear gene position, intraand intergenic interactions, and finally, transcription factors (lineage-specific, signal-induced, and generic) determines the timing of gene expression as well as gene transcriptional dynamics (i.e., transcriptional bursting). The gene will start to transcribe only when all the requirements for transcriptional initiation are accomplished. Therefore, at a single-cell level, a given signal may not gradually increase transcription of an inducible gene locus but rather enable a digital transition from an "off" to an "on" state of gene expression (Fig. 10B) (Stevense et al. 2010). For example, triggering of 3T3 mouse fibroblast cells with the proinflammatory cytokine TNF $\alpha$ results in activation of the transcription factor NF- $\kappa \mathrm{B}$ and primary "open" promoter response genes in a digital-like fashion (Covert et al. 2005; Tay et al. 2010). Although the number of cells responding to $\mathrm{TNF} \alpha$ is proportional to the TNF $\alpha$ concentration, the activated cells display equal levels of NF- $\kappa \mathrm{B}$ and primary gene expression (Fig. 10B). However, at the population level, a transition from an "off" to "on" state will not occur simultaneously, thus giving the impression of gene expression being increased in a gradual, analog fashion. The latter analog response, however, appears to describe the expression of TNF $\alpha$-induced secondary response genes (Fig. 10C). The expression of secondary response genes (i.e., with "closed" promoters), opposite of the primary response genes, follows the analog-like pattern wherein an increase in concentration increases the level of gene expression within an individual cell (Fig. 10C) (Covert et al. 2005; Tay et al. 2010).

Future studies of individual cell epigenomes combined with comprehensive studies of gene expression at a singlecell level may provide a statistical foundation to support a model that could predict the dynamics of gene expression during inflammation.

\subsection{Regulation of Inflammatory Gene Expression by Signal-Induced RNA Elongation}

A reason for digital versus analog patterns of primary and secondary TNF $\alpha$-inducible genes and, perhaps, other inducible gene responses might lie in the differential coordi- 


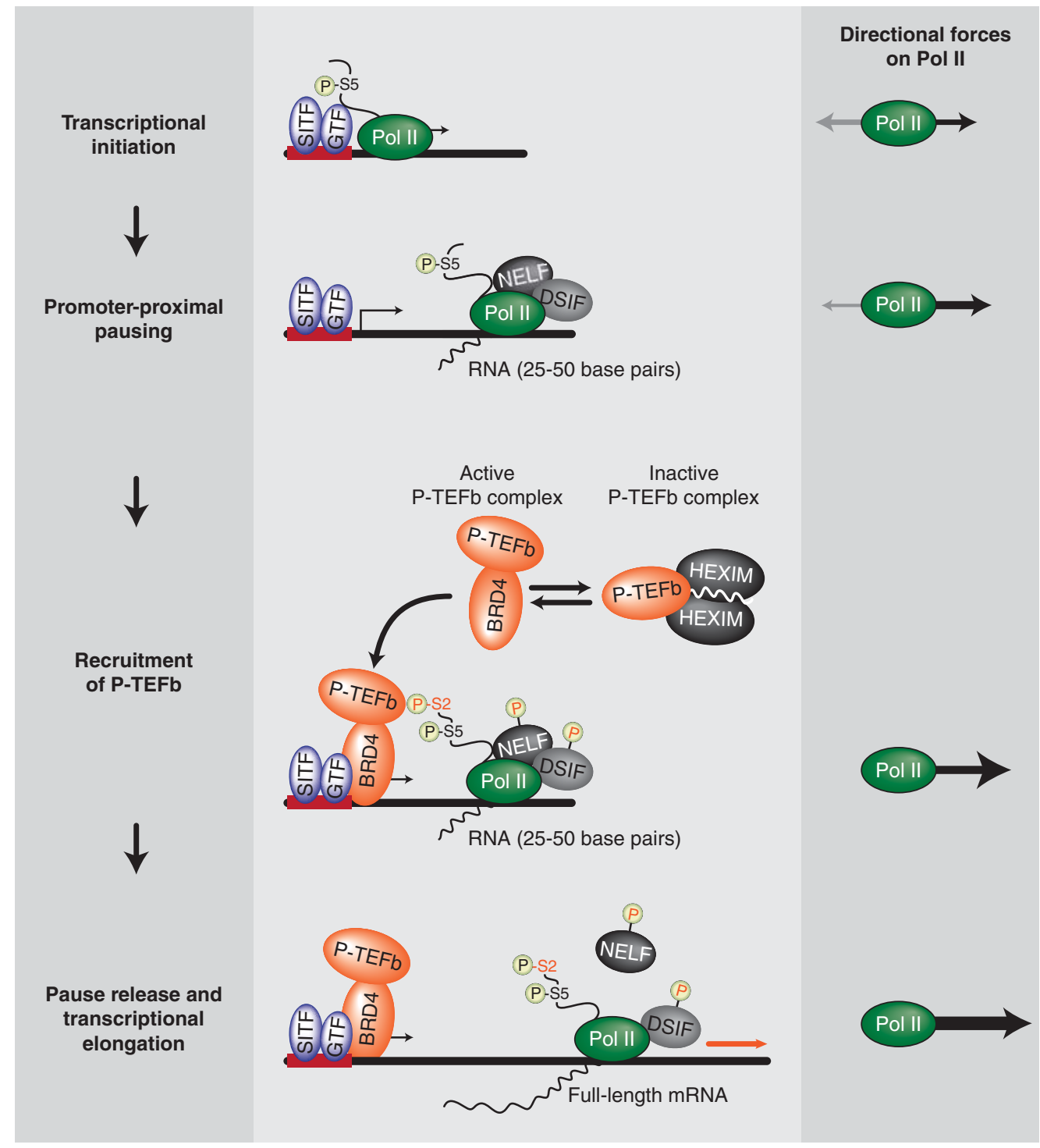

Figure 11. Coupling of transcriptional initiation to elongation. The key biochemical events that control the transition from transcriptional initiation to elongation are shown. The arrows shown to the right illustrate the combinatorial nature of forces acting on the RNA polymerase II (Pol II) at various phases of RNA expression. SITF, signal induced transcription factor; GTF, general transcription factors; P-S5, phosphorylation of serine 5 in the carboxyterminal domain (CTD) of Pol II; NELF, negative elongation factor; DSIF, DRB sensitivity-inducing factor; P-TEFb, positive transcription-elongation factor-b; BRD4, bromodomain-containing protein 4; HEXIM, hexamethylene bis-acetimide inducible 1; P-S2, phosphorylation of serine 2 in the CTD of Pol II.

nation between transcriptional initiation and elongation at primary and secondary gene loci. In both types of genes, elongation requires the activity of factors that enable RNA Pol II processivity. These factors could be schematically assigned to a few key regulatory hubs that determine the efficiency of elongation (Fig. 11). The first of these regulatory hubs is at gene promoters where RNA Pol II comes under the control of factors that significantly slow or halt elongation (Zhou et al. 2012). Two negative elongation factors, the 5,6-dichloro-1- $\beta$-D-ribofuranosylbenzimida- zole (DRB) sensitivity-inducing factor (DSIF) and negative elongation factor (NELF), associate with RNA Pol II during initiation, leading to the generation of poised polymerases (Adelman and Lis 2012). The amount of promoter-proximal RNA Pol II determines the size of the polymerase pool potentially available for elongation.

The release of Pol II into elongation depends on the activity and/or amount of gene-bound cyclin-dependent kinase-pausing machinery (i.e., $\mathrm{P}-\mathrm{TEFb}$ and associated factors), which enables RNA Poll II processivity (Peterlin and 
Price 2006; Zhou et al. 2012). The amount of P-TEFb available for RNA Pol II release and activation relies on the level of gene activity. This is effectively regulated in a "demand and supply" fashion that is gauged through the amount of promoter-bound BRD4. BRD4 is a "reader" of the acetylation state of histone $\mathrm{H} 4$ at gene promoters (Fig. 11) (Zeng and Zhou 2002; Peterlin and Price 2006; Mujtaba et al. 2007; Filippakopoulos et al. 2012). Indeed, the amount of BRD4 bound to chromatin is a key determinant of the gene transition from initiation into elongation. BRD4 plays a dual role in the transition because it not only mediates the release of $\mathrm{P}-\mathrm{TEFb}$ from an inhibitory macromolecular complex in a graded fashion but also recruits it to chromatin via binding to acetylated histone $\mathrm{H} 4$. The inhibitory complex includes 7SK snRNP, the RNA-bound hexamethylene bis-acetamide-inducible (HEXIM) protein, and other proteins that stabilize the complex (Fig. 11) (Zhou et al. 2012). The binding of the CDK9 kinase of P-TEFb to the inhibitory domains of HEXIM1 or HEXIM2 render it inactive (Zhou et al. 2012). Binding of the carboxy-terminal portion of BRD4 to P-TEFb, however, releases this protein from the complex and is followed by the activation of RNA elongation (Fig. 11). In summary, both the amount of RNA Pol II stalled at the promoter and the amount of P-TEFb delivered to release the stalled RNA Pol II will determine the initial efficiency of RNA elongation. At later stages of RNA synthesis, other elongation factors become engaged into the complex and support elongation at a steady $3.8 \mathrm{~kb} / \mathrm{min}$ rate for up to 2 million base pairs (Luo et al. 2012; Zhou et al. 2012).

mRNA elongation is important for controlling the inducible inflammatory gene expression program in response to Toll-like receptor signaling in macrophages. In the absence of stimulation, RNA Pol II generates low levels of fulllength but unspliced and untranslatable transcripts at many of the CpG-rich primary response genes (Hargreaves et al. 2009). Gene induction is accomplished through the signaldependent recruitment of P-TEFb by BRD4, which itself recognizes the inducibly acquired histone $\mathrm{H} 4$ acetylation on lysines 5, 8, and 12 (Hargreaves et al. 2009). This results in robust RNA Pol II phosphorylation on serine 2 by P-TEFb (Fig. 11) and production of high levels of fully spliced mature mRNA transcripts.

Interaction between BRD4 and acetylated histones is mediated by the evolutionary conserved $\sim 110$ aa-long bromodomain, which is present in two tandemly arranged modules (BDI and BDII) in BRD4. This configuration is also present in the related BRD2 and BRD3 proteins of the BET family (Zeng and Zhou 2002; Mujtaba et al. 2007; Filippakopoulos et al. 2012). Interruption of the bromodomain interaction with acetylated histones by highly selective synthetic antagonists (i.e., JQ1 or I-BET) disrupts

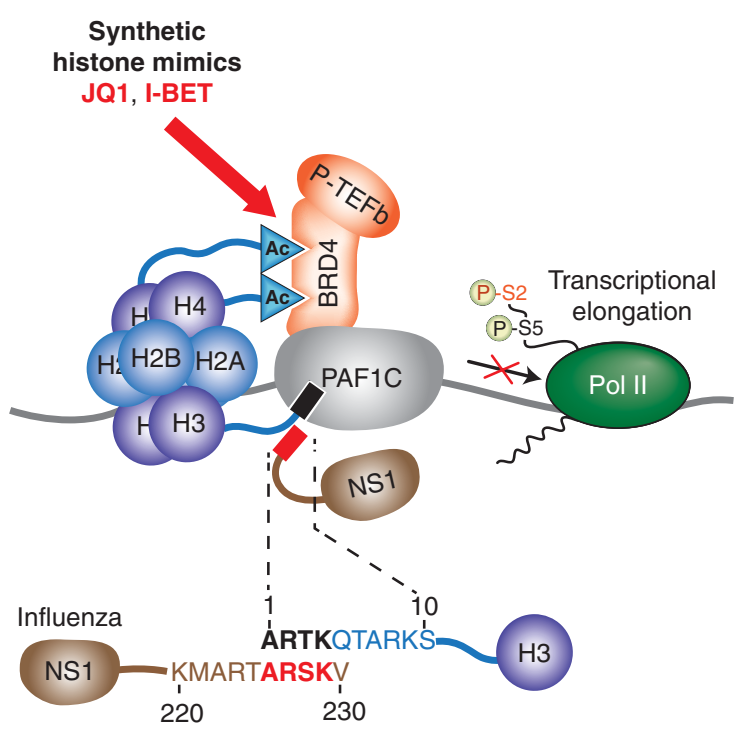

Figure 12. Control of gene expression by "histone mimics." Nucleosomes contribute to the control of signal-induced transcriptional elongation by recruiting BRD4 and its associated P-TEFb complex via the acetylated amino-terminal tail of histone $\mathrm{H} 4$ and the PAF1 complex (PAF1C) via the amino-terminal ARTK motif of histone H3. The small molecules JQ1 and I-BET (red arrow) function as synthetic histone mimics by preventing the recruitment of BRD4 to promoters through competitive binding to BRD4 bromodomains. The carboxy-terminal ARSK sequence (red rectangle) of the influenza NS1 protein acts as a histone mimic by competing with the amino-terminal tail of histone 3 for binding to the PAF1 complex.

BETassociation with chromatin, followed by changes in the expression of numerous proinflammatory genes such as $I L$ 12 or IL-6 (Fig. 12) (Filippakopoulos et al. 2010; Nicodeme et al. 2010). Thus, both primary and secondary genes are dependent on BRD4 and perhaps other BET proteins, as suggested by the reduced expression of primary and secondary LPS-induced genes during small interfering RNA (siRNA)-mediated knockdown of BRD4 or multiple BET proteins (Fig. 9) (Hargreaves et al. 2009; Medzhitov and Horng, 2009). However, treatment with I-BET had a highly selective impact on secondary response genes and minimal effect on primary LPS-inducible gene expression. This may be because I-BET predominantly affects a pool of BET proteins that are not yet bound to chromatin, while having a limited impact on histone-bound BET proteins. The chromatin-bound pool of BET proteins at primary gene loci might be sufficient for transcriptional elongation. Contrary to the primary response genes, recruitment of BET proteins to secondary response genes follows signal-induced chromatin remodeling and transcriptional initiation. By that time, a significant fraction of BET proteins are likely to be trapped by I-BET, thus limiting the amount of BET proteins available for RNA synthesis. 


\section{7 "HISTONE MIMICRY" AND ITS IMPLICATION FOR REGULATION OF INFLAMMATION}

The ability of I-BET to interfere with proinflammatory gene expression suggests a more general possibility of interference with gene expression by using synthetic or natural molecules that could mimic the interaction of histones with effector proteins. Mammalian cells express large numbers of proteins that carry sequences similar to the amino-terminal portions of histones, that is, short amino acid sequences such as ARTK or ARKS (Fig. 12) (A Tarakhovsky, unpubl.). In some cases, histone-like sequences ("histone mimics") can fully recapitulate the protein-binding capacity of its histone $\mathrm{H} 3$ counterpart, such as the mimicking motif within the methyltransferase G9a protein shown to contain similarity to histone $\mathrm{H} 3$, and results in the binding to self and autocatalytical methylation (Sampath et al. 2007). Histone mimics may also serve as recognition modules that enable posttranslational modification of nonhistone proteins for purposes not directly linked to chromatin function at all (Lee et al. 2012). In any scenario, the proteins carrying histone mimics may compete with histones for histone-modifying enzymes as well as for histone-binding proteins.

Histone mimics are present in numerous bacteria or viral proteins (A Tarakhovsky, unpubl.). The physiological significance of the pathogen-derived histone mimics has been underscored by the effect of a histone $\mathrm{H} 3$ mimicking domain present in the carboxy-terminal portion of the influenza protein NS1 (with a sequence of ARSK vs. the amino-terminal endogenous H3 sequence ARTK) (Fig. 12) (Marazzi et al. 2012). In humans, most of the NS1 action probably takes place in the nucleus, where the amount of NS1 protein can reach levels close to the amounts of nucleosomes $\left(5 \times 10^{6}\right.$ vs. $3 \times 10^{7}$, respectively) (Marazzi et al. 2012). The NS1 histone mimic domain binds directly to the PAF1 protein (Marazzi et al. 2012), an essential subunit of the multiprotein elongation complex PAF1C (Fig. 12) (Kim et al. 2009; Jaehning 2010; Smith and Shilatifard 2010). Binding of NS1 to PAF1 inhibits elongation of virus-induced genes, thus contributing to the attenuation of a host's antiviral response (Marazzi et al. 2012). The presumed mode of NS1 action on PAF1C-mediated elongation is likely to reflect a competition between histone $\mathrm{H} 3$ and NS1 for PAF1, resulting in a reduction of PAF1 abundance at the transcribed gene loci (Fig. 12) (Marazzi et al. 2012). Parallel experiments showed that siRNA-mediated knockdown of PAF1 expression results in the selective down-regulation of inducible antiviral gene expression, confirming that PAF1 is important in the antiviral transcriptional response (Marazzi et al. 2012).

The discovery of histone mimicry is a relatively novel finding. It has shown that it is not only important as a mechanism of pathogen adaption but may provide novel therapeutic avenues to target the regulation of the immune response.

\section{CONCLUDING REMARKS}

Healthy immunity thrives on the robustness of immune cell generation, functional diversity of the differentiated immune cells, and a high level of immune cell adaptability to environmental changes. Although operating as a system, immunity relies on the individual cell's preexisting or adaptive ability to tune to the constantly changing environment. This feature of immune cells implies the existence of mechanisms that enhance diversification of the individual cells while maintaining the integrity of the system. In this context, epigenetic mechanisms must capacitate cell adaptation without affecting cell differentiation. Failure to adapt, or an exaggerated response, will cause systemic immune system failures followed by the development of immune disorders. The epigenetic mechanisms that are supposed to control the memory of the environmental impact may also contribute to the persistence of disease-associated phenotypes, even in the absence of the initial trigger. In this context, it would be attractive to consider the possibility of treating chronic inflammatory states by pharmacological "erasure" of the diseased epigenetic landscape, followed by restoration of the healthy gene expression patterns.

There is growing evidence suggesting that pathogens can affect host immunity through the interference with multiple epigenetic processes. Histone mimicry by pathogen-derived proteins offers a mechanistic understanding of the short- and long-term effects of infections on the organism. Accordingly, the identification of proteins that bind to the pathogen-derived histone mimics may guide the identification of novel targets for therapeutic intervention of gene expression. In this context, the rational design of small molecules that mimic histone binding to various effector proteins may lead to the development of drugs that affect gene expression in a highly selective fashion and in accordance with the epigenetic state of individual genes.

\section{REFERENCES}

* Reference is also in this collection.

Adelman K, Lis JT. 2012. Promoter-proximal pausing of RNA polymerase II: Emerging roles in metazoans. Nat Rev Genet 13: $720-$ 731.

Bacher CP, Guggiari M, Brors B, Augui S, Clerc P, Avner P, Eils R, Heard E. 2006. Transient colocalization of X-inactivation centres accompanies the initiation of X inactivation. Nat Cell Biol 8: 293299.

Bai L, Morozov AV. 2010. Gene regulation by nucleosome positioning. Trends Genet 26: 476-483. 
Bai L, Ondracka A, Cross FR. 2011. Multiple sequence-specific factors generate the nucleosome-depleted region on CLN2 promoter. Mol Cell 42: 465-476.

Balazsi G, van Oudenaarden A, Collins JJ. 2011. Cellular decision making and biological noise: From microbes to mammals. Cell 144: 910-925.

Bassing CH, Swat W, Alt FW. 2002. The mechanism and regulation of chromosomal V(D)J recombination. Cell 109: S45-S55.

Bereshchenko OR, Gu W, Dalla-Favera R. 2002. Acetylation inactivates the transcriptional repressor BCL6. Nat Genet 32: 606-613.

Bhatt DM, Pandya-Jones A, Tong AJ, Barozzi I, Lissner MM, Natoli G, Black DL, Smale ST. 2012. Transcript dynamics of proinflammatory genes revealed by sequence analysis of subcellular RNA fractions. Cell 150: $279-290$.

Blake WJ, Kærn M, Cantor CR, Collins JJ. 2003. Noise in eukaryotic gene expression. Nature 422: 633-637.

Bolland DJ, Wood AL, Johnston CM, Bunting SF, Morgan G, Chakalova L, Fraser PJ, Corcoran AE. 2004. Antisense intergenic transcription in $\mathrm{V}(\mathrm{D}) \mathrm{J}$ recombination. Nat Immunol 5: 630-637.

Bracken AP, Pasini D, Capra M, Prosperini E, Colli E, Helin K. 2003. EZH2 is downstream of the pRB-E2F pathway, essential for proliferation and amplified in cancer. EMBO J 22: 5323-5335.

Bussmann LH, Schubert A, Vu Manh TP, De Andres L, Desbordes SC, Parra M, Zimmermann T, Rapino F, Rodriguez-Ubreva J, Ballestar E, et al. 2009. A robust and highly efficient immune cell reprogramming system. Cell Stem Cell 5: 554-566.

Cai L, Dalal CK, Elowitz MB. 2008. Frequency-modulated nuclear localization bursts coordinate gene regulation. Nature 455: 485-490.

Cairns BR. 2009. The logic of chromatin architecture and remodelling at promoters. Nature 461: 193-198.

Chakraborty T, Perlot T, Subrahmanyam R, Jani A, Goff PH, Zhang Y, Ivanova I, Alt FW, Sen R. 2009. A 220-nucleotide deletion of the intronic enhancer reveals an epigenetic hierarchy in immunoglobulin heavy chain locus activation. J Exp Med 206: 1019-1027.

Chubb JR, Liverpool TB. 2010. Bursts and pulses: Insights from single cell studies into transcriptional mechanisms. Curr Opin Genet Dev 20: $478-484$

Cobaleda C, Jochum W, Busslinger M. 2007. Conversion of mature B cells into $\mathrm{T}$ cells by dedifferentiation to uncommitted progenitors. Nature 449: 473-477.

Covert MW, Leung TH, Gaston JE, Baltimore D. 2005. Achieving stability of lipopolysaccharide-induced NF- $\mathrm{BB}$ activation. Science 309: 18541857.

Decker T, Pasca di Magliano M, McManus S, Sun Q, Bonifer C, Tagoh H, Busslinger M. 2009. Stepwise activation of enhancer and promoter regions of the B cell commitment gene Pax5 in early lymphopoiesis. Immunity 30: 508-520.

Degner SC, Verma-Gaur J, Wong TP, Bossen C, Iverson GM, Torkamani A, Vettermann C, Lin YC, Ju Z, Schulz D, et al. 2011. CCCTC-binding factor (CTCF) and cohesin influence the genomic architecture of the Igh locus and antisense transcription in pro-B cells. Proc Natl Acad Sci 108: 9566-9571.

Delogu A, Schebesta A, Sun Q, Aschenbrenner K, Perlot T, Busslinger M. 2006. Gene repression by Pax5 in B cells is essential for blood cell homeostasis and is reversed in plasma cells. Immunity 24: 269-281.

Deniaud E, Bickmore WA. 2009. Transcription and the nuclear periphery: Edge of darkness? Curr Opin Genet Dev 19: 187-191.

De Santa F, Totaro MG, Prosperini E, Notarbartolo S, Testa G, Natoli G. 2007. The histone $\mathrm{H} 3$ lysine-27 demethylase Jmjd3 links inflammation to inhibition of polycomb-mediated gene silencing. Cell 130: 10831094.

de Wit E, van Steensel B. 2009. Chromatin domains in higher eukaryotes: Insights from genome-wide mapping studies. Chromosoma 118: 2536.

Dias S, Mansson R, Gurbuxani S, Sigvardsson M, Kee BL. 2008. E2A proteins promote development of lymphoid-primed multipotent progenitors. Immunity 29: 217-227.
Ebert A, McManus S, Tagoh H, Medvedovic J, Salvagiotto G, Novatchkova M, Tamir I, Sommer A, Jaritz M, Busslinger M. 2011. The distal $\mathrm{V}_{\mathrm{H}}$ gene cluster of the Igh locus contains distinct regulatory elements with Pax5 transcription factor-dependent activity in pro-B cells. Immunity 34: 175-187.

Edmunds JW, Mahadevan LC, Clayton AL. 2008. Dynamic histone H3 methylation during gene induction: HYPB/Setd2 mediates all H3K36 trimethylation. EMBO J 27: 406-420.

Eldar A, Elowitz MB. 2010. Functional roles for noise in genetic circuits. Nature 467: 167-173.

Fang TC, Schaefer U, Mecklenbrauker I, Stienen A, Dewell S, Chen MS, Rioja I, Parravicini V, Priniha RK, Chandwani R, et al. 2012. Histone H3 lysine 9 di-methylation as an epigenetic signature of the interferon response. J Exp Med 209: 661-669.

Filippakopoulos P, Qi J, Picaud S, Shen Y, Smith WB, Fedorov O, Morse EM, Keates T, Hickman TT, Felletar I, et al. 2010. Selective inhibition of BET bromodomains. Nature 468: 1067-1073.

Filippakopoulos P, Picaud S, Mangos M, Keates T, Lambert JP, BarsyteLovejoy D, Felletar I, Volkmer R, Muller S, Pawson T, et al. 2012. Histone recognition and large-scale structural analysis of the human bromodomain family. Cell 149: 214-231.

Foster SL, Hargreaves DC, Medzhitov R. 2007. Gene-specific control of inflammation by TLR-induced chromatin modifications. Nature 447: 972-978.

Fuxa M, Skok J, Souabni A, Salvagiotto G, Roldán E, Busslinger M. 2004. Pax5 induces $V$-to- $D J$ rearrangements and locus contraction of the immunoglobulin heavy-chain gene. Genes Dev 18: 411-422.

Gilchrist DA, Adelman K. 2012. Coupling polymerase pausing and chromatin landscapes for precise regulation of transcription. Biochim Biophys Acta 1819: 700-706.

Gilchrist M, Thorsson V, Li B, Rust AG, Korb M, Roach JC, Kennedy K, Hai T, Bolouri H, Aderem A. 2006. Systems biology approaches identify ATF3 as a negative regulator of Toll-like receptor 4. Nature 441: $173-178$.

Guenther MG, Lawton LN, Rozovskaia T, Frampton GM, Levine SS, Volkert TL, Croce CM, Nakamura T, Canaani E, Young RA. 2008. Aberrant chromatin at genes encoding stem cell regulators in human mixed-lineage leukemia. Genes Dev 22: 3403-3408.

Guo L, Hu-Li J, Paul WE. 2004. Probabilistic regulation of IL-4 production in Th2 cells: Accessibility at the Il4 locus. Immunity 20: 193-203.

Guo C, Yoon HS, Franklin A, Jain S, Ebert A, Cheng HL, Hansen E, Despo O, Bossen C, Vettermann C, et al. 2011. CTCF-binding elements mediate control of V(D)J recombination. Nature 477: 424-430.

Györy I, Boller S, Nechanitzky R, Mandel E, Pott S, Liu E, Grosschedl R. 2012. Transcription factor Ebfl regulates differentiation stage-specific signaling, proliferation, and survival of B cells. Genes Dev 26: 668682.

Hadjur S, Williams LM, Ryan NK, Cobb BS, Sexton T, Fraser P, Fisher AG, Merkenschlager M. 2009. Cohesins form chromosomal cis-interactions at the developmentally regulated IFNG locus. Nature 460: $410-413$.

Hargreaves DC, Horng T, Medzhitov R. 2009. Control of inducible gene expression by signal-dependent transcriptional elongation. Cell 138: 129-145.

Hawwari A, Krangel MS. 2005. Regulation of TCR $\delta$ and $\alpha$ repertoires by local and long-distance control of variable gene segment chromatin structure. J Exp Med 202: 467-472.

Hesslein DGT, Pflugh DL, Chowdhury D, Bothwell ALM, Sen R, Schatz DG. 2003. Pax5 is required for recombination of transcribed, acetylated, 5' IgH V gene segments. Genes Dev 17: 37-42.

Hewitt SL, Farmer D, Marszalek K, Cadera E, Liang HE, Xu Y, Schlissel MS, Skok JA. 2008. Association between the Igk and Igh immunoglobulin loci mediated by the 3 ' Igk enhancer induces 'decontraction' of the Igh locus in pre-B cells. Nat Immunol 9: 396-404.

Hewitt SL, Yin B, Ji Y, Chaumeil J, Marszalek K, Tenthorey J, Salvagiotto G, Steinel N, Ramsey LB, Ghysdael J, et al. 2009. RAG-1 and ATM 
coordinate monoallelic recombination and nuclear positioning of immunoglobulin loci. Nat Immunol 10: 655-664.

Jaehning JA. 2010. The Paf1 complex: Platform or player in RNA polymerase II transcription? Biochim Biophys Acta 1799: 379-388.

Jankovic M, Casellas R, Yannoutsos N, Wardemann H, Nussenzweig MC. 2004. RAGs and regulation of autoantibodies. Annu Rev Immunol 22: $485-501$.

Jhunjhunwala S, van Zelm MC, Peak MM, Cutchin S, Riblet R, van Dongen JJM, Grosveld FG, Knoch TA, Murre C. 2008. The 3D structure of the immunoglobulin heavy-chain locus: Implications for longrange genomic interactions. Cell 133: 265-279.

Jhunjhunwala S, van Zelm MC, Peak MM, Murre C. 2009. Chromatin architecture and the generation of antigen receptor diversity. Cell 138: 435-448.

Ji Y, Resch W, Corbett E, Yamane A, Casellas R, Schatz DG. 2010. The in vivo pattern of binding of RAG1 and RAG2 to antigen receptor loci. Cell 141: 419-431.

Keats JJ, Reiman T, Maxwell CA, Taylor BJ, Larratt LM, Mant MJ, Belch AR, Pilarski LM. 2003. In multiple myeloma, $\mathrm{t}(4 ; 14)(\mathrm{p} 16 ; \mathrm{q} 32)$ is an adverse prognostic factor irrespective of FGFR3 expression. Blood 101: $1520-1529$.

Kim J, Guermah M, McGinty RK, Lee JS, Tang Z, Milne TA, Shilatifard A, Muir TW, Roeder RG. 2009. RAD6-mediated transcription-coupled $\mathrm{H} 2 \mathrm{~B}$ ubiquitylation directly stimulates $\mathrm{H} 3 \mathrm{~K} 4$ methylation in human cells. Cell 137: 459-471.

Kosak ST, Skok JA, Medina KL, Riblet R, Le Beau MM, Fisher AG, Singh H. 2002. Subnuclear compartmentalization of immunoglobulin loci during lymphocyte development. Science 296: 158-162.

Kuo AJ, Cheung P, Chen K, Zee BM, Kioi M, Lauring J, Xi Y, Park BH, Shi X, Garcia BA, et al. 2011. NSD2 links dimethylation of histone H3 at lysine 36 to oncogenic programming. Mol Cell 44: 609-620.

Kwak H, Fuda NJ, Core LJ, Lis JT. 2013. Precise maps of RNA polymerase reveal how promoters direct initiation and pausing. Science 339: 950953.

Laiosa CV, Stadtfeld M, Xie H, de Andres-Aguayo L, Graf T. 2006. Reprogramming of committed $\mathrm{T}$ cell progenitors to macrophages and dendritic cells by $\mathrm{C} / \mathrm{EBP} \alpha$ and PU.1 transcription factors. Immunity 25: 731-744.

Lam FH, Steger DJ, O'Shea EK. 2008. Chromatin decouples promoter threshold from dynamic range. Nature 453: 246-250.

Larson DR. 2011. What do expression dynamics tell us about the mechanism of transcription? Curr Opin Genet Dev 21: 591-599.

Lee JM, Lee JS, Kim H, Kim K, Park H, Kim JY, Lee SH, Kim IS, Kim J, Lee $\mathrm{M}$, et al. 2012. EZH2 generates a methyl degron that is recognized by the DCAF1/DDB1/CUL4 E3 ubiquitin ligase complex. Mol Cell 48: $572-586$.

* Li E, Zhang Y. 2014. DNA methylation in mammals. Cold Spring Harb Perspect Biol doi: 10.1101/cshperspect.a019133.

Li L, Leid M, Rothenberg EV. 2010. An early T cell lineage commitment checkpoint dependent on the transcription factor Bcl11b. Science 329: 89-93.

Lill NL, Grossman SR, Ginsberg D, DeCaprio J, Livingston DM. 1997. Binding and modulation of p53 by p300/CBP coactivators. Nature 387: $823-827$.

Liu H, Cheng EH, Hsieh JJ. 2009. MLL fusions: Pathways to leukemia. Cancer Biol Ther 8: 1204-1211.

Liu Z, Widlak P, Zou Y, Xiao F, Oh M, Li S, Chang MY, Shay JW, Garrard WT. 2006. A recombination silencer that specifies heterochromatin positioning and Ikaros association in the immunoglobulin $\kappa$ locus. Immunity 24: 405-415.

Liu H, Schmidt-Supprian M, Shi Y, Hobeika E, Barteneva N, Jumaa H, Pelanda R, Reth M, Skok J, Rajewsky K, et al. 2007. Yin Yang 1 is a critical regulator of B-cell development. Genes Dev 21: 1179-1189.

Luo Z, Lin C, Shilatifard A. 2012. The super elongation complex (SEC) family in transcriptional control. Nat Rev Mol Cell Biol 13: 543-547.
Maheshri N, O'Shea EK. 2007. Living with noisy genes: How cells function reliably with inherent variability in gene expression. Annu Rev Biophys Biomol Struct 36: 413-434.

Malin S, McManus S, Cobaleda C, Novatchkova M, Delogu A, Bouillet P, Strasser A, Busslinger M. 2010. Role of STAT5 in controlling cell survival and immunoglobulin gene recombination during pro-B cell development. Nat Immunol 11: 171-179.

Mar BG, Bullinger L, Basu E, Schlis K, Silverman LB, Döhner K, Armstrong SA. 2012. Sequencing histone-modifying enzymes identifies UTX mutations in acute lymphoblastic leukemia. Leukemia 26: $1881-1883$.

Marazzi I, Ho JS, Kim J, Manicassamy B, Dewell S, Albrecht RA, Seibert CW, Schaefer U, Jeffrey KL, Prinjha RK, et al. 2012. Suppression of the antiviral response by an influenza histone mimic. Nature 483: $428-$ 433.

Matthews AG, Kuo AJ, Ramón-Maiques S, Han S, Champagne KS, Ivanov D, Gallardo M, Carney D, Cheung P, Ciccone DN, et al. 2007. RAG2 PHD finger couples histone H3 lysine 4 trimethylation with V(D)J recombination. Nature 450: 1106-1110.

McManus S, Ebert A, Salvagiotto G, Medvedovic J, Sun Q, Tamir I, Jaritz M, Tagoh H, Busslinger M. 2011. The transcription factor Pax5 regulates its target genes by recruiting chromatin-modifying proteins in committed B cells. EMBO J 30: 2388-2404.

Medvedovic J, Ebert A, Tagoh H, Busslinger M. 2011. Pax5: A master regulator of B cell development and leukemogenesis. Adv Immunol 111: $179-206$.

Medvedovic J, Ebert A, Tagoh H, Tamir IM, Schwickert TA, Novatchkova M, Sun Q, Huis in 't Veld PJ, Guo C, Yoon HS, et al. 2013. Flexible longrange loops in the $\mathrm{V}_{\mathrm{H}}$ gene region of the Igh locus facilitate the generation of a diverse antibody repertoire. Immunity 39: 229-244.

Medzhitov R. 2008. Origin and physiological roles of inflammation. Nature 454: 428-435.

Medzhitov R, Horng T. 2009. Transcriptional control of the inflammatory response. Nat Rev Immunol 9: 692-703.

Morin RD, Johnson NA, Severson TM, Mungall AJ, An J, Goya R, Paul JE, Boyle M, Woolcock BW, Kuchenbauer F, et al. 2010. Somatic mutations altering EZH2 (Tyr641) in follicular and diffuse large B-cell lymphomas of germinal-center origin. Nat Genet 42: 181-185.

Morin RD, Mendez-Lago M, Mungall AJ, Goya R, Mungall KL, Corbett RD, Johnson NA, Severson TM, Chiu R, Field M, et al. 2011. Frequent mutation of histone-modifying genes in non-Hodgkin lymphoma. Nature 476: 298-303.

Mujtaba S, Zeng L, Zhou MM. 2007. Structure and acetyl-lysine recognition of the bromodomain. Oncogene 26: 5521-5527.

Mullighan CG, Goorha S, Radtke I, Miller CB, Coustan-Smith E, Dalton JD, Girtman K, Mathew S, Ma J, Pounds SB, et al. 2007. Genome-wide analysis of genetic alterations in acute lymphoblastic leukaemia. $\mathrm{Na}$ ture 446: 758-764.

Mullighan CG, Zhang J, Kasper LH, Lerach S, Payne-Turner D, Phillips LA, Heatley SL, Holmfeldt L, Collins-Underwood JR, Ma J, et al. 2011. $C R E B B P$ mutations in relapsed acute lymphoblastic leukaemia. $\mathrm{Na}$ ture 471: 235-239.

Murphy KM. 2005. Fate vs choice: The immune system reloaded. Immunol Res 32: 193-200.

Nativio R, Wendt KS, Ito Y, Huddleston JE, Uribe-Lewis S, Woodfine K, Krueger C, Reik W, Peters JM, Murrell A. 2009. Cohesin is required for higher-order chromatin conformation at the imprinted IGF2-H19 locus. PLoS Genet 5: e1000739.

Natoli G, Ghisletti S, Barozzi I. 2011. The genomic landscapes of inflammation. Genes Dev 25: 101-106.

Ng SY-M, Yoshida T, Zhang J, Georgopoulos K. 2009. Genome-wide lineage-specific transcriptional networks underscore Ikaros-dependent lymphoid priming in hematopoietic stem cells. Immunity 30: 493-507.

Nicodeme E, Jeffrey KL, Schaefer U, Beinke S, Dewell S, Chung CW, Chandwani R, Marazzi I, Wilson P, Coste H, et al. 2010. Suppression 
of inflammation by a synthetic histone mimic. Nature 468: 11191123.

Ntziachristos P, Tsirigos A, Van Vlierberghe P, Nedjic J, Trimarchi T, Flaherty MS, Ferres-Marco D, da Ros V, Tang Z, Siegle J, et al. 2012. Genetic inactivation of the Polycomb repressive complex 2 in $\mathrm{T}$ cell acute lymphoblastic leukemia. Nat Med 18: 298-301.

Nutt SL, Kee BL. 2007. The transcriptional regulation of B cell lineage commitment. Immunity 26: 715-725.

Nutt SL, Heavey B, Rolink AG, Busslinger M. 1999. Commitment to the B-lymphoid lineage depends on the transcription factor Pax5. Nature 401: $556-562$.

Ogryzko VV, Schiltz RL, Russanova V, Howard BH, Nakatani Y. 1996. The transcriptional coactivators p300 and CBP are histone acetyltransferases. Cell 87: 953-959.

Oguro H, Yuan J, Ichikawa H, Ikawa T, Yamazaki S, Kawamoto H, Nakauchi H, Iwama A. 2010. Poised lineage specification in multipotential hematopoietic stem and progenitor cells by the polycomb protein Bmil. Cell Stem Cell 6: 279-286.

Okada Y, Feng Q, Lin Y, Jiang Q, Li Y, Coffield VM, Su L, Xu G, Zhang Y. 2005. hDOT1L links histone methylation to leukemogenesis. Cell 121: $167-178$.

Paixao T, Carvalho TP, Calado DP, Carneiro J. 2007. Quantitative insights into stochastic monoallelic expression of cytokine genes. Immunol Cell Biol 85: 315-322.

Pasqualucci L, Dominguez-Sola D, Chiarenza A, Fabbri G, Grunn A, Trifonov V, Kasper LH, Lerach S, Tang H, Ma J, et al. 2011. Inactivating mutations of acetyltransferase genes in B-cell lymphoma. Nature 471: $189-195$.

Pedraza JM, Paulsson J. 2008. Effects of molecular memory and bursting on fluctuations in gene expression. Science 319: 339-343.

Perlot T, Alt FW. 2008. Cis-regulatory elements and epigenetic changes control genomic rearrangements of the IgH locus. Adv Immunol 99: $1-32$.

Perlot T, Alt FW, Bassing CH, Suh H, Pinaud E. 2005. Elucidation of IgH intronic enhancer functions via germ-line deletion. Proc Natl Acad Sci 102: $14362-14367$.

Peterlin BM, Price DH. 2006. Controlling the elongation phase of transcription with P-TEFb. Mol Cell 23: 297-305.

Phillips JE, Corces VG. 2009. CTCF: Master weaver of the genome. Cell 137: 1194-1211.

Radtke F, Fasnacht N, Macdonald HR. 2010. Notch signaling in the immune system. Immunity 32: 14-27.

Raj A, van Oudenaarden A. 2009. Single-molecule approaches to stochastic gene expression. Annu Rev Biophys 38: 255-270.

Ramirez-Carrozzi VR, Braas D, Bhatt DM, Cheng CS, Hong C, Doty KR, Black JC, Hoffmann A, Carey M, Smale ST. 2009. A unifying model for the selective regulation of inducible transcription by $\mathrm{CpG}$ islands and nucleosome remodeling. Cell 138: 114-128.

Raser JM, O'Shea EK. 2005. Noise in gene expression: Origins, consequences, and control. Science 309: 2010-2013.

Revilla-i-Domingo R, Bilic I, Vilagos B, Tagoh H, Ebert A, Tamir IM, Smeenk L, Trupke J, Sommer A, Jaritz M, et al. 2012. The B-cell identity factor Pax5 regulates distinct transcriptional programmes in early and late B lymphopoiesis. EMBO J 31: 3130-3146.

Ribeiro de Almeida C, Stadhouders R, de Bruijn MJ, Bergen IM, Thongjuea S, Lenhard B, van Ijcken W, Grosveld F, Galjart N, Soler E, et al. 2011. The DNA-binding protein CTCF limits proximal Vк recombination and restricts $\kappa$ enhancer interactions to the immunoglobulin $\kappa$ light chain locus. Immunity 35: 501-513.

Roldán E, Fuxa M, Chong W, Martinez D, Novatchkova M, Busslinger M, Skok JA. 2005. Locus 'decontraction' and centromeric recruitment contribute to allelic exclusion of the immunoglobulin heavy-chain gene. Nat Immunol 6: 31-41.

Romanow WJ, Langerak AW, Goebel P, Wolvers-Tettero ILM, van Dongen JJM, Feeney AJ, Murre C. 2000. E2A and EBF act in synergy with the $\mathrm{V}(\mathrm{D}) \mathrm{J}$ recombinase to generate a diverse immunoglobulin repertoire in nonlymphoid cells. Mol Cell 5: 343-353.
Saccani S, Natoli G. 2002. Dynamic changes in histone H3 Lys 9 methylation occurring at tightly regulated inducible inflammatory genes. Genes Dev 16: 2219-2224.

Sampath SC, Marazzi I, Yap KL, Sampath SC, Krutchinsky AN, Mecklenbrauker I, Viale A, Rudensky E, Zhou MM, Chait BT, et al. 2007. Methylation of a histone mimic within the histone methyltransferase G9a regulates protein complex assembly. Mol Cell 27: 596-608.

Sayegh C, Jhunjhunwala S, Riblet R, Murre C. 2005. Visualization of looping involving the immunoglobulin heavy-chain locus in developing B cells. Genes Dev 19: 322-327.

Schlimgen RJ, Reddy KL, Singh H, Krangel MS. 2008. Initiation of allelic exclusion by stochastic interaction of Tcrb alleles with repressive nuclear compartments. Nat Immunol 9: 802-809.

Seitan VC, Hao B, Tachibana-Konwalski K, Lavagnolli T, Mira-Bontenbal H, Brown KE, Teng G, Carroll T, Terry A, Horan K, et al. 2011. A role for cohesin in T-cell-receptor rearrangement and thymocyte differentiation. Nature 476: 467-471.

Shaffer AL, Lin K-I, Kuo TC, Yu X, Hurt EM, Rosenwald A, Giltnane JM, Yang L, Zhao H, Calame K, et al. 2002. Blimp-1 orchestrates plasma cell differentiation by extinguishing the mature $\mathrm{B}$ cell gene expression program. Immunity 17: 51-62.

Simon C, Chagraoui J, Krosl J, Gendron P, Wilhelm B, Lemieux S, Boucher G, Chagnon P, Drouin S, Lambert R, et al. 2012. A key role for $\mathrm{EZH} 2$ and associated genes in mouse and human adult T-cell acute leukemia. Genes Dev 26: 651-656.

Skok JA, Gisler R, Novatchkova M, Farmer D, de Laat W, Busslinger M. 2007. Reversible contraction by looping of the Tcrb and Tcra loci in rearranging thymocytes. Nat Immunol 8: 378-387.

Smale ST. 2010a. Pioneer factors in embryonic stem cells and differentiation. Curr Opin Genet Dev 20: 519-526.

Smale ST. 2010b. Selective transcription in response to an inflammatory stimulus. Cell 140: 833-844.

Smith E, Shilatifard A. 2010. The chromatin signaling pathway: Diverse mechanisms of recruitment of histone-modifying enzymes and varied biological outcomes. Mol Cell 40: 689-701.

Sneeringer CJ, Scott MP, Kuntz KW, Knutson SK, Pollock RM, Richon VM, Copeland RA. 2010. Coordinated activities of wild-type plus mutant EZH2 drive tumor-associated hypertrimethylation of lysine 27 on histone H3 (H3K27) in human B-cell lymphomas. Proc Natl Acad Sci 107: 20980-20985.

Splinter E, Heath H, Kooren J, Palstra R-J, Klous P, Grosveld F, Galjart N, de Laat W. 2006. CTCF mediates long-range chromatin looping and local histone modification in the $\beta$-globin locus. Genes Dev 20: 2349 2354.

Stanhope-Baker P, Hudson KM, Shaffer AL, Constantinescu A, Schlissel MS. 1996. Cell type-specific chromatin structure determines the targeting of V(D)J recombinase activity in vitro. Cell 85: 887-897.

Stevense M, Muramoto T, Muller I, Chubb JR. 2010. Digital nature of the immediate-early transcriptional response. Development 137: 579584.

Su I-H, Basavaraj A, Krutchinsky AN, Hobert O, Ullrich A, Chait BT, Tarakhovsky A. 2003. Ezh2 controls B cell development through histone H3 methylation and Igh rearrangement. Nat Immunol 4: 124131.

Takahashi K, Yamanaka S. 2006. Induction of pluripotent stem cells from mouse embryonic and adult fibroblast cultures by defined factors. Cell 126: $663-676$.

Tay S, Hughey JJ, Lee TK, Lipniacki T, Quake SR, Covert MW. 2010. Single-cell NF- $\mathrm{BB}$ dynamics reveal digital activation and analogue information processing. Nature 466: 267-271.

Ting CN, Olson MC, Barton KP, Leiden JM. 1996. Transcription factor GATA-3 is required for development of the T-cell lineage. Nature 384: $474-478$.

van Haaften G, Dalgliesh GL, Davies H, Chen L, Bignell G, Greenman C, Edkins S, Hardy C, O’Meara S, Teague J, et al. 2009. Somatic mutations of the histone H3K27 demethylase gene UTX in human cancer. Nat Genet 41: 521-523. 
M. Busslinger and A. Tarakhovsky

Weber BN, Chi AW-S, Chavez A, Yashiro-Ohtani Y, Yang Q, Shestova O, Bhandoola A. 2011. A critical role for TCF-1 in T-lineage specification and differentiation. Nature 476: 63-68.

Xiang Y, Zhou X, Hewitt SL, Skok JA, Garrard WT. 2011. A multifunctional element in the mouse $I g \kappa$ locus that specifies repertoire and $I g$ loci subnuclear location. J Immunol 186: 5356-5366.

Xie H, Ye M, Feng R, Graf T. 2004. Stepwise reprogramming of B cells into macrophages. Cell 117: 663-676.

Yancopoulos GD, Alt FW. 1985. Developmentally controlled and tissuespecific expression of unrearranged $\mathrm{V}_{\mathrm{H}}$ gene segments. Cell 40: 271281.

Yap DB, Chu J, Berg T, Schapira M, Cheng SW, Moradian A, Morin RD, Mungall AJ, Meissner B, Boyle M, et al. 2011. Somatic mutations at EZH2 Y641 act dominantly through a mechanism of selectively altered PRC2 catalytic activity, to increase H3K27 trimethylation. Blood 117: $2451-2459$.

Ye S-K, Agata Y, Lee H-C, Kurooka H, Kitamura T, Shimizu A, Honjo T, Ikuta K. 2001. The IL-7 receptor controls the accessibility of the TCR $y$ locus by Stat 5 and histone acetylation. Immunity 15: 813-823.
Yosef N, Regev A. 2011. Impulse control: Temporal dynamics in gene transcription. Cell 144: 886-896.

Zak DE, Aderem A. 2009. Systems biology of innate immunity. Immunol Rev 227: 264-282.

Zeng L, Zhou MM. 2002. Bromodomain: An acetyl-lysine binding domain. FEBS Lett 513: 124-128.

Zhang J, Ding L, Holmfeldt L, Wu G, Heatley SL, Payne-Turner D, Easton J, Chen X, Wang J, Rusch M, et al. 2012a. The genetic basis of early T-cell precursor acute lymphoblastic leukaemia. Nature 481: 157163.

Zhang J, Jackson AF, Naito T, Dose M, Seavitt J, Liu F, Heller EJ, Kashiwagi M, Yoshida T, Gounari F, et al. 2012b. Harnessing of the nucleosome-remodeling-deacetylase complex controls lymphocyte development and prevents leukemogenesis. Nat Immunol 13: $86-94$.

Zhao M, Zhang J, Phatnani H, Scheu S, Maniatis T. 2012. Stochastic expression of the interferon- $\beta$ gene. PLoS Biol 10: e1001249.

Zhou Q, Li T, Price DH. 2012. RNA polymerase II elongation control. Annu Rev Biochem 81: 119-143. 


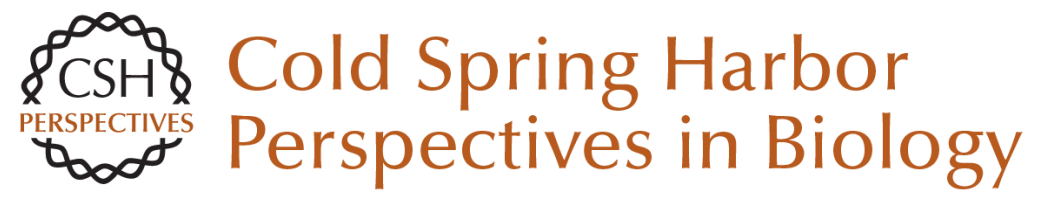

\section{Epigenetic Control of Immunity}

Meinrad Busslinger and Alexander Tarakhovsky

Cold Spring Harb Perspect Biol 2014; doi: 10.1101/cshperspect.a019307

Subject Collection Epigenetics

Metabolic Signaling to Chromatin Shelley L. Berger and Paolo Sassone-Corsi

Histone and DNA Modifications as Regulators of Neuronal Development and Function Stavros Lomvardas and Tom Maniatis

Histone Modifications and Cancer James E. Audia and Robert M. Campbell

Epigenetics and Human Disease Huda Y. Zoghbi and Arthur L. Beaudet

Induced Pluripotency and Epigenetic Reprogramming Konrad Hochedlinger and Rudolf Jaenisch

Long-Range Chromatin Interactions Job Dekker and Tom Misteli

RNAi and Heterochromatin Assembly Robert Martienssen and Danesh Moazed

Dosage Compensation in Drosophila John C. Lucchesi and Mitzi I. Kuroda
Epigenetic Determinants of Cancer Stephen B. Baylin and Peter A. Jones

Maintenance of Epigenetic Information Geneviève Almouzni and Howard Cedar

A Structural Perspective on Readout of Epigenetic Histone and DNA Methylation Marks Dinshaw J. Patel

The Necessity of Chromatin: A View in

Perspective Vincenzo Pirrotta

Germline and Pluripotent Stem Cells Wolf Reik and M. Azim Surani

Comprehensive Catalog of Currently Documented Histone Modifications Yingming Zhao and Benjamin A. Garcia

Epigenetic Regulation of Chromatin States in Schizosaccharomyces pombe Robin C. Allshire and Karl Ekwall

Histone Variants and Epigenetics Steven Henikoff and M. Mitchell Smith

For additional articles in this collection, see http://cshperspectives.cshlp.org/cgi/collection/

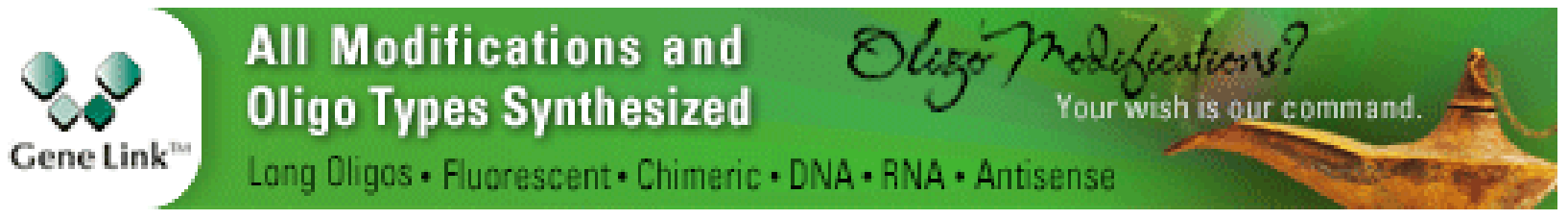

Copyright (C) 2014 Cold Spring Harbor Laboratory Press; all rights reserved 
For additional articles in this collection, see http://cshperspectives.cshlp.org/cgi/collection/

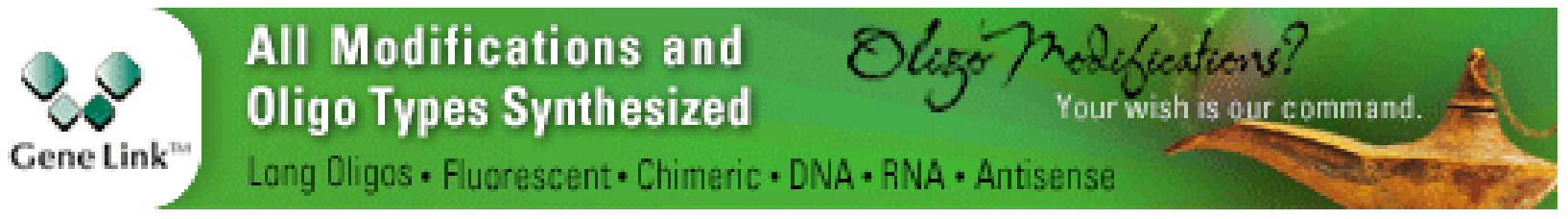

Copyright @ 2014 Cold Spring Harbor Laboratory Press; all rights reserved 